\title{
Mesoscale Controls on the Mountainside Snow Line
}

\author{
JUSTIN R. MindeR* AND DALE R. DURRAN \\ Department of Atmospheric Sciences, University of Washington, Seattle, Washington \\ GERARD H. ROE \\ Department of Earth and Space Sciences, University of Washington, Seattle, Washington
}

(Manuscript received 7 December 2010, in final form 22 February 2011)

\begin{abstract}
Observations show that on a mountainside the boundary between snow and rain, the snow line, is often located at an elevation hundreds of meters below its elevation in the free air upwind. The processes responsible for this mesoscale lowering of the snow line are examined in semi-idealized simulations with a mesoscale numerical model and in simpler theoretical models. Spatial variations in latent cooling from melting precipitation, in adiabatic cooling from vertical motion, and in the melting distance of frozen hydrometeors are all shown to make important contributions. The magnitude of the snow line drop, and the relative importance of the responsible processes, depends on properties of the incoming flow and terrain geometry. Results suggest that the depression of the snow line increases with increasing temperature, a relationship that, if present in nature, could act to buffer mountain hydroclimates against the impacts of climate warming. The simulated melting distance, and hence the snow line, depends substantially on the choice of microphysical parameterization, pointing to an important source of uncertainty in simulations of mountain snowfall.
\end{abstract}

\section{Introduction and background}

One of the most fundamental aspects of mountain weather and climate is the snow line, loosely the boundary between low-elevation rainfall and highelevation snowfall. The precise location that the snow line intersects the topography during storms is central in determining the navigability of mountain roadways and railways, the risk of landslides and avalanches, and the quality of mountain recreation. Additionally, the snow line modulates the effect of storms on mountain streamflow, since snow often accumulates on the ground whereas rainfall typically produces runoff much more quickly, potentially leading to flooding (White et al. 2002; Hamlet and Lettenmaier 2007; Lundquist et al.

\footnotetext{
* Current affiliation: Department of Geology and Geophysics, Yale University, New Haven, Connecticut.

Corresponding author address: Justin R. Minder, Department of Geology and Geophysics, Box 208109, Yale University, New Haven, CT 06520-8109.

E-mail: justin.minder@yale.edu
}

2008). Furthermore, the distribution of snow line elevations among storms controls the seasonal accumulation of mountain snowpack (e.g., Minder 2010b), a crucial water resource for many communities (e.g., Barnett et al. 2005). Changes of just a few hundred meters in the snow line elevation have major impacts. For example, White et al. (2002) modeled that a rise in the snow line of about $2000 \mathrm{ft}(610 \mathrm{~m})$ during a storm would triple runoff for three mountainous river basins in northern California. Minder (2010b) modeled that the approximately $200-\mathrm{m}$ rise in the average snow line elevation associated with $1{ }^{\circ} \mathrm{C}$ of climate warming acts to reduce annual snowpack accumulation in the western Cascade Mountains of Washington by about $15 \%-18 \%$.

Despite the large impacts of modest changes in the snow line, forecasters and researchers often estimate precipitation phase over mountains using methods that do not account for the myriad processes that control precipitation formation, phase change, and fallout over mountains. For instance, hydrological models often estimate precipitation phase based on surface temperature relationships, ignoring the impact of atmospheric processes aloft (e.g., Anderson 1976; Westrick and Mass 
2001; Hamlet et al. 2005; Elsner et al. 2010). Furthermore, weather forecasts and climate studies often infer and predict mountain snow line elevations using vertical temperature profiles either from coarse-resolution models that poorly resolve mountainous topography and its effect on airflow (e.g., Diaz et al. 2003; Arendt et al. 2009; White et al. 2010) or from sounding observations taken tens to hundreds of kilometers away (e.g., Svoma 2011; Minder 2010b). The above, relatively crude, methodologies are used in part because the behavior of, and physical controls on, mountain snow lines are poorly characterized and understood. Motivated by the central role of the snow line in mountain weather and climate, this study aims to use modeling and theory to sharpen this understanding.

\section{a. Terminology}

To understand the snow line, a key variable is the $0^{\circ} \mathrm{C}$ isotherm elevation $Z_{0 \mathrm{C}}$, since this is where frozen precipitation starts to melt as it falls. In this study $Z_{0 \mathrm{C}}$ is defined as the elevation where the atmospheric temperature profile $T(z)$ crosses $0^{\circ} \mathrm{C}$ (e.g., Fig. 1a). ${ }^{1}$ The region below $Z_{0 \mathrm{C}}$ where melting is occurring is referred to as the melting layer.

The snow line is not a sharp boundary since frozen, partially melted, and liquid precipitation may coexist, and thus it may be defined in various ways. This study focuses on the snow line elevation $Z_{S}$, defined as the elevation where $50 \%$ of the frozen hydrometeor mass (quantified by the mixing ratio of snow and graupel: $q_{s, g}=q_{s}+q_{g}$ ) falling through $Z_{0 \mathrm{C}}$ has been lost, presumably by melting into rain (e.g., Fig. $1 \mathrm{~b}$ ). ${ }^{2}$

Directly measuring $Z_{S}$ aloft is challenging and requires missions with specially equipped aircraft. Consequently, most observations of $Z_{S}$ are indirect, relying on remote measurements using radars. During stratiform precipitation, radar reflectivities often show a strong enhancement in the region of melting, referred to as the radar bright band (BB). This feature occurs as a result of aggregation of hydrometeors, changes in complex index of refraction, and changes in fall speed that occur during melting (e.g., Houze 1993). The BB typically begins just below $Z_{0 \mathrm{C}}$ and roughly coincides with the melting layer. The bright band elevation $Z_{\mathrm{BB}}$ is defined as the elevation in the $\mathrm{BB}$ with maximum

\footnotetext{
${ }^{1}$ In general, isothermal layers or temperature inversions may complicate the definition of $Z_{0 \mathrm{C}}$, but such features are absent from the simulations presented here.

${ }^{2}$ Other valuable measures of the snow-rain transition are possible. One alternative is the elevation at which the vertical flux of hydrometeors is half-frozen and half-liquid. Results from section 3 are qualitatively similar if this measure is used instead (see Minder 2010a).
}

(a)

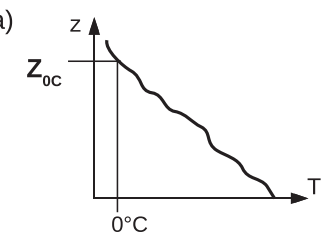

(c)

(b)

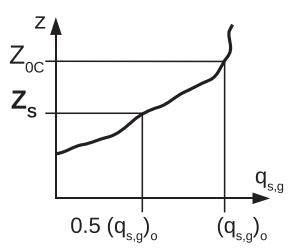

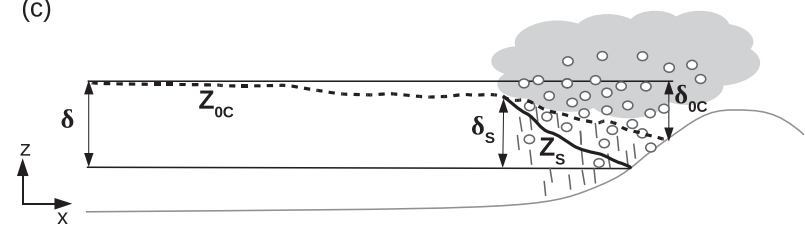

FIG. 1. Schematic illustration of how the main quantities considered in this study are defined. (a) Determination of $Z_{0 \mathrm{C}}$ from $T(z)$. (b) Determination of $Z_{S}$ from a profile of $q_{s, g}(z)$. (c) Determination of $\delta_{0 \mathrm{C}}, \delta_{\mathrm{S}}$, and $\delta$ from upwind and mountainside values of $Z_{0 \mathrm{C}}$ (thick dashed line) and $Z_{S}$ (thick solid line). Thin horizontal lines are drawn at the elevation of the upwind $Z_{0 \mathrm{C}}$ and the mountainside $Z_{S}$.

reflectivity (following, e.g., White et al. 2002, 2010) and is typically the best remotely sensed proxy for $Z_{S}$ available.

This study quantifies mesoscale orographic influences on the snow line by mapping out $Z_{0 \mathrm{C}}$ and $Z_{S}$ and comparing their values where they intersect the mountain to their upwind values (Fig. 1c). Orographic influences on temperature are quantified by $\delta_{0 \mathrm{C}}$, the displacement between the mountainside $Z_{0 \mathrm{C}}$ and its upwind value (Fig. 1c). Likewise, orographic influences on the snow line are quantified as $\delta_{S}$, the displacement between the mountainside $Z_{S}$ and its upwind value (Fig. 1c). Understanding $\delta_{S}$ is relevant to the interpretation of radar datasets that measure $Z_{\mathrm{BB}}$ upwind of and over mountains (e.g., White et al. 2002, 2010; Lundquist et al. 2008). Since orographic influences on $Z_{0 \mathrm{C}}$ may extend farther upwind than the precipitation region, the full orographic influence on the snow line is quantified as $\delta$, the displacement between the mountainside $Z_{S}$ and the upwind $Z_{0 \mathrm{C}}$ (Fig. 1c). Understanding the behavior of $\delta$ is particularly important for relating temperature profiles from soundings and global models to mountain snow lines (e.g., Diaz et al. 2003; Arendt et al. 2009; Svoma 2011; Minder 2010b).

\section{b. Previous work}

Some of the earliest observational work to analyze the rain-snow transition over mountains was presented by Marwitz $(1983$, 1987). These studies examined orographic storms over the northern Sierra Nevada using ground-based C-band radar, special soundings, and in situ aircraft data. Over the windward slopes, during stratiform storms, $Z_{0 \mathrm{C}}$ was found to descend by at least $400 \mathrm{~m}$ (Fig. 2a; see Marwitz 1987), and the radar BB was found to increase several $100 \mathrm{~m}$ in depth as it approached the mountain (Fig. 2b; see Marwitz 1983). 
(a)

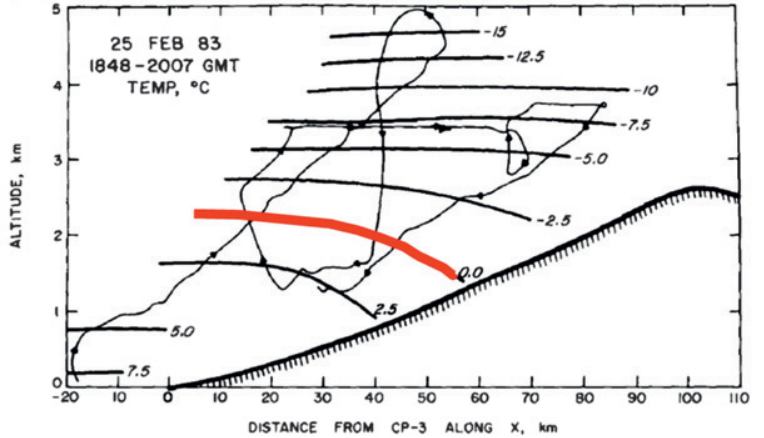

(c)

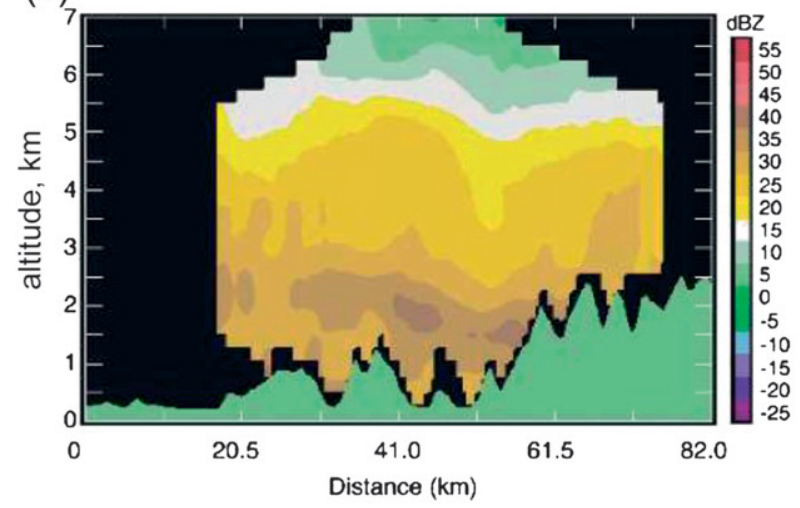

(b)

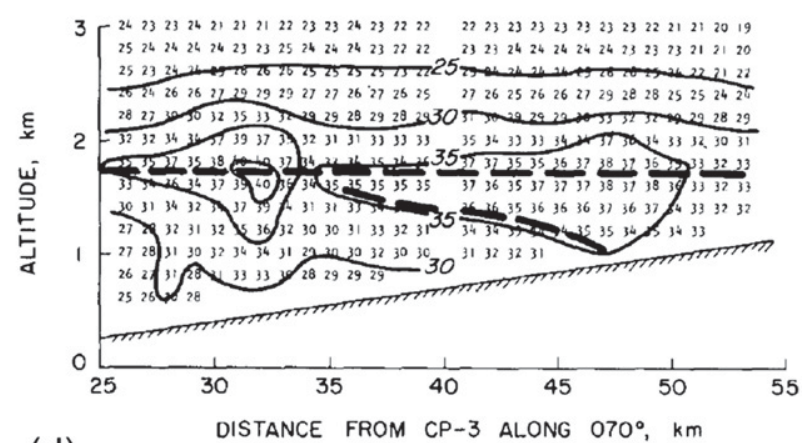

(d)

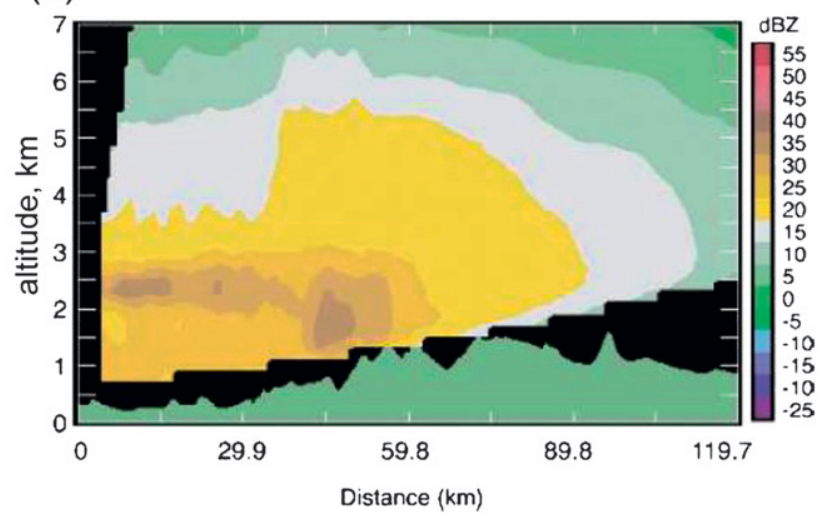

FIG. 2. Figures from previous observational studies showing drops in $Z_{0 \mathrm{C}}$ and $Z_{\mathrm{BB}}$. All panels are vertical cross sections along the prevailing wind direction with winds impinging from the left. The terrain profiles are shown along the bottom. (a) Isotherms $\left({ }^{\circ} \mathrm{C}\right.$, with $Z_{0 \mathrm{C}}$ in red) analyzed from aircraft in situ measurements (flight track shown with thin line) over the northern Sierra Nevada on 25 Feb 1983 (adapted from Marwitz 1987). (b) Radar reflectivity ( $\mathrm{dB} Z_{e}$, contoured) from RHI scans with the National Oceanic and Atmospheric Administration (NOAA) CP-3 radar over the northern Sierra Nevada on 15 Feb 1980 (from Marwitz 1983). (c) Reflectivity (dBZ $Z_{e}$, filled contours) from NOAA P-3 airborne radar analysis over the Lago Maggiore region of the Italian Alps on 21 Oct 1999 (from Medina et al. 2005). (d) Reflectivity ( $\mathrm{dBZ}_{e}$, filled contours) from RHI scans with the S-Pol radar over the Oregon Cascades on 28 Nov 2001 (from Medina et al. 2005). All panels copyright American Meteorological Society.

The features described by Marwitz $(1983,1987)$ are not unique to storms over the Sierra Nevada. This was made evident by Medina et al. (2005), who examined ground-based and airborne radar data from three stratiform storms: one over the Alps and two over the Oregon Cascades. As shown in Figs. $2 \mathrm{c}$ and $2 \mathrm{~d}$, they found a similar deepening of the $\mathrm{BB}$ and a drop in $Z_{\mathrm{BB}}$ of several hundred meters over the windward slopes of both of these ranges.

The mesoscale modification of $Z_{S}$ also appears consistently in observations of many storms, distinguishing it as a climatological feature. Lundquist et al. (2008) and Kingsmill et al. (2008) used several years of radar profiler observations to characterize the spatial variability of $Z_{S}$ in the same region of the Sierra Nevada studied by Marwitz (1983, 1987). Lundquist et al. (2008) showed that on average $Z_{\mathrm{BB}}$ drops by $73 \mathrm{~m}$ between a coastal radar profiler and a profiler at the base of the Sierra (although $Z_{\mathrm{BB}}$ may drop even more between the radar and the windward slopes). Kingsmill et al. (2008) found that $Z_{\mathrm{BB}}$ above the windward slopes is on average approximately $200 \mathrm{~m}$ lower than upwind of the terrain. Furthermore, large storm-to-storm variability was observed: the windward $Z_{\mathrm{BB}}$ was found to range from $1 \mathrm{~km}$ lower to $200 \mathrm{~m}$ higher than the upwind $Z_{\mathrm{BB}}$ (Kingsmill et al. 2008).

Few modeling studies have focused in detail on $Z_{0 \mathrm{C}}$ and $Z_{S}$ over mountains. Wei and Marwitz (1996) conducted 2D simulations of a single orographic blizzard over the Colorado Front Range, focusing on the impact of melting, while Colle (2004) showed a drop in $Z_{S}$ in a number of idealized simulations of flow over $2 \mathrm{D}$ ridges.

\section{c. Possible mechanisms}

A number of physical explanations have been proposed for the mesoscale structure of $Z_{S}$ observed over mountains. This study will focus on three possible mechanisms. 


\section{1) LATENT COOLING FROM MELTING PRECIPITATION}

The first of these mechanisms relies on spatial variations in cooling of the air by the melting of precipitation $Q_{\text {melt }}$. During stratiform precipitation over flat terrain, the upper portion of the melting layer is often cooled to near-freezing temperatures by the uptake of latent heat during melting. This localized cooling can lead to an unstable stratification, which in turn induces convective overturning and a deepening of the layer of cooled air and melting (Findeisen 1940). In situ aircraft observations have shown near-isothermal $0^{\circ} \mathrm{C}$ layers, approximately $200 \mathrm{~m}$ thick, atop the melting layer and the radar $\mathrm{BB}$, with unstable stratification below (Stewart et al. 1984). Simple analytic models_considering the energy balance and convective adjustment of a vertical columnhave been used to understand how the depth of the $0^{\circ} \mathrm{C}$ isothermal layer increases with precipitation intensity and duration (Lin and Stewart 1986; Unterstrasser and Zängl 2006).

During storms over the Sierra, Marwitz $(1983,1987)$ observed soundings with deep near- $0^{\circ} \mathrm{C}$ layers and cited these as evidence that the drop in $Z_{\mathrm{BB}}\left(\right.$ and $Z_{S}$ ) over the windward slope is due to spatial variations in $Q_{\text {melt }}$; he argued that orographically enhanced precipitation rates over the mountain slopes lead to more $Q_{\text {melt }}$, deeper $0^{\circ} \mathrm{C}$ layers, and lower $Z_{S}$ than in the air upwind. The modeling studies of Wei and Marwitz (1996) and Colle (2004) also cited $Q_{\text {melt }}$ as important in determining the mesoscale structure of $Z_{S}$ and $Z_{0 \mathrm{C}}$.

\section{2) MICROPHYSICAL MELTING DISTANCE}

Another hypothesis, not directly discussed in previous work, is that the drop in $Z_{S}$ can be explained, in part, by spatial variations in the vertical distance over which frozen hydrometeors melt (i.e., $Z_{0 \mathrm{C}}-Z_{S}$, hereafter $D_{\text {melt }}$ ), which can vary widely. For instance, in northern California $Z_{\mathrm{BB}}$ is on average displaced about $230-237 \mathrm{~m}$ below $Z_{0 \mathrm{C}}$, but the displacement can range from 122 to $427 \mathrm{~m}$ (White et al. 2010). Controls on $D_{\text {melt }}$ include snowflake size, relative humidity, snow density, and atmospheric lapse rate (Matsuo and Sasyo 1981; Mitra et al. 1990). Mitra et al. (1990) modeled that a snowflake $10 \mathrm{~mm}$ in diameter would descend about $100 \mathrm{~m}$ farther below $Z_{0 \mathrm{C}}$ before melting than a 5 -mm snowflake, demonstrating that snowflake size is a key control on $D_{\text {melt }}$.

The upwind region of an orographic cloud-where vertical velocities and supersaturations are modestmay tend to have frozen hydrometeors that are smaller in diameter and less rimed than those found in the region just over the windward slope-where vertical velocities and supersaturation are larger (Rauber 1992;
Garvert et al. 2005). If such an increase in hydrometeor size and riming occurs, it could cause $D_{\text {melt }}$ to increase toward the mountain by 1) increasing the mass of individual frozen hydrometeors, and thus the amount of time required for melting, and 2) increasing the fall speed of frozen hydrometeors, although this effect will depend on the crystal type and degree of riming (Locatelli and Hobbs 1974; Barthazy and Schefold 2006) as well as the horizontal variations in vertical wind speed.

\section{3) AdiABATIC COOLING}

Adiabatic cooling $Q_{\text {ad }}$, which occurs as air parcels are forced to rise over a topographic barrier and expand, could also play an important role (Bell and Bosart 1988; Medina et al. 2005; Kingsmill et al. 2008). If air parcels passing over a mountain have risen and cooled with respect to the air at the same elevation upwind, $Z_{0 \mathrm{C}}$ and $Z_{S}$ will drop.

Several other processes, not mentioned above, may also modify $Z_{S}$. For instance, preexisting cold air that is blocked and unable to pass over a mountain could result in a lowering of $Z_{0 \mathrm{C}}$ and $Z_{S}$ (e.g., Bell and Bosart 1988; Bousquet and Smull 2003; Medina et al. 2005). Steenburgh et al. (1997) showed that cold continental air can be channeled through passes in the Cascade Mountains, in opposition to the synoptic-scale flow, resulting in a localized lowering of $Z_{0 \mathrm{C}}$ and $Z_{S}$. Other studies have shown how the geometry of mountain valleys can amplify the tendency for $Q_{\text {melt }}$ to lower $Z_{S}$ (e.g., Steinacker 1983; Unterstrasser and Zängl 2006). For simplicity this study focuses on unblocked flows and mechanisms responsible for determining $Z_{S}$ averaged along the length of a mountain, and thus the preceding mechanisms will be neglected despite their potential importance.

\section{d. Questions}

As described above, previous research has made it clear that mesoscale processes over the windward slopes of mountain ranges regularly act to lower $Z_{S}$ relative to the upwind value by several hundred meters. While a number of physical mechanisms have been suggested, no study has yet considered these mechanisms together and in depth, assessed their relative importance, examined their interactions, or used them to explain the storm-tostorm variability observed in the climatology.

This study uses a numerical model of mountain airflow and precipitation combined with theory to address the following:

(i) How do $D_{\text {melt }}, Q_{\text {melt }}$, and $Q_{\text {ad }}$ interact to determine $Z_{S}$ on a mountainside? 
(ii) How do upwind conditions and topographic form cause the mesoscale structure of $Z_{S}$ to vary storm to storm, with climate, and between mountains?

(iii) How robust are predictions of $Z_{S}$ to the choice of model configuration?

\section{Numerical model}

To represent the various dynamic, thermodynamic, and microphysical processes influencing $Z_{S}$ requires a full mesoscale numerical weather prediction model capable of simulating all these processes and their interactions. Accordingly, the Weather Research and Forecasting (WRF) model (version 3.0.1, Skamarock et al. 2008) is employed to conduct experiments. Since these experiments are focused on isolating and understanding the physical mechanisms that control $Z_{S}$ (as opposed to simulating $Z_{S}$ for a specific storm), the model is used in a semi-idealized configuration, with simplified topography and incoming flow characteristics.

The experiments simulate steady, stably stratified, near-saturated, nonhydrostatic airflow and precipitation over a smooth mountain barrier. The simulations are initialized with a horizontally uniform, hydrostatically balanced atmospheric profile. In the troposphere the temperature profile is constructed by prescribing a value for the upwind surface temperature $T_{s}$ and then iteratively solving for temperatures at higher levels, using the methods outlined in Miglietta and Rotunno (2005, 2006). A spatially uniform value of moist stability $N_{m}$ is prescribed, using the definition of Lalas and Einaudi (1973) and Durran and Klemp (1982):

$$
N_{m}^{2}=\frac{g}{T}\left(\Gamma_{m}-\Gamma\right)\left(1+\frac{L_{v} q_{\mathrm{vs}}}{R_{d} T}\right)-\frac{g}{1+q_{w}} \frac{d q_{w}}{d z},
$$

where $T$ is temperature, $\Gamma$ is the environmental lapse rate $(-d T / d z), \Gamma_{m}$ is the moist-adiabatic lapse rate, $L_{v}$ is the latent heat of vaporization for water, $R_{d}$ is the ideal gas constant for dry air, $q_{\mathrm{vs}}$ is the saturated water vapor mixing ratio, $q_{w}$ is the total water mixing ratio $\left(q_{\mathrm{vs}}+q_{L}\right.$, where $q_{L}$ is the condensed water mixing ratio), and $g$ is the acceleration due to gravity. A uniform relative humidity $(\mathrm{RH})$ is prescribed throughout the troposphere (with respect to ice for temperatures $<0^{\circ} \mathrm{C}$ ). The sounding has a tropopause at $8 \mathrm{~km}$, above which is a stratosphere where $\mathrm{RH}$ is reduced to $20 \%$ and a dry stability $N_{d}$ of $0.02 \mathrm{~s}^{-1}$ is prescribed.

The experiments are quasi-2D, and the terrain takes the form of a ridge that is infinitely long in the crosswind dimension $y$ and has a profile described by

$$
h(x)= \begin{cases}\frac{h_{m}}{16}\left[1+\cos \left(\pi \frac{x}{4 a}\right)\right]^{4}, & \text { if }\left|\frac{x}{4 a}\right| \leq 1 \\ 0, & \text { otherwise. }\end{cases}
$$

A mountain height $h_{m}$ of $1.5 \mathrm{~km}$ and a half-width $a$ of $40 \mathrm{~km}$ are used for most simulations, giving terrain roughly similar in dimensions to the Cascade Mountains.

Third-order Runge-Kutta time stepping is used, with fifth-order horizontal and third-order vertical advection. The boundary conditions are open in the $x$ direction and periodic in the $y$ direction. The time step is $5 \mathrm{~s}$ for advection and physics, and $5 / 6 \mathrm{~s}$ for acoustic modes. The upper boundary condition is a constant pressure surface, with the vertical velocity damping layer described by Klemp et al. (2008) applied over the top $10 \mathrm{~km}$ to prevent the reflection of gravity waves off the model top (Fig. 3a). The bottom boundary condition is free-slip. The absence of surface friction simplifies the airflow and makes the analysis more straightforward, but it also may limit the realism of some results (see section 6a).

The vertical discretization consists of 201 levels of terrain-following $\eta$ coordinate, with spacing $\Delta z$ varying from $17 \mathrm{~m}$ near the surface to about $450 \mathrm{~m}$ at the base of the damping layer, and up to $2 \mathrm{~km}$ at the model top at $z=25 \mathrm{~km}$. The horizontal grid spacing $\Delta x=\Delta y$ is $2 \mathrm{~km}$, and there are 1250 grid points in $x$ and 3 in $y$, yielding a domain $2500 \mathrm{~km}$ in $x$ and $6 \mathrm{~km}$ in $y$ (Fig. 3a).

The Coriolis force is applied to perturbations from the initial wind profile, which is assumed to be in geostrophic balance. This is equivalent to subtracting a geostrophically balanced reference state from the governing equations, and follows Colle (2004) and Kirshbaum and Smith (2008). The $f$-plane approximation is made, with $f=10^{-4} \mathrm{~s}^{-1}$. The Coriolis force is not applied to normal velocities at the open lateral boundaries.

For the control simulation, cloud and precipitation microphysics are parameterized with the Thompson et al. scheme (Thompson et al. 2008), a bulk mixedphase scheme that predicts the number concentration of cloud ice and the mixing ratios of water vapor, cloud liquid water, cloud ice, rain, snow, and graupel. Unique features of the scheme include a nonspherical shape assumed for snow, a snow size distribution represented with the sum of exponential and gamma functions, and an acceleration of snow and graupel fall speeds in the melting layer to mimic partially melted hydrometeors. This scheme is used because it is one of the most sophisticated schemes available in WRF, its sensitivities have been extensively documented for the problem of orographic precipitation (e.g., Thompson et al. 2004, 2008; Lin and Colle 2009), and it has proved capable of accurately simulating mountain snowfall (Ikeda et al. 

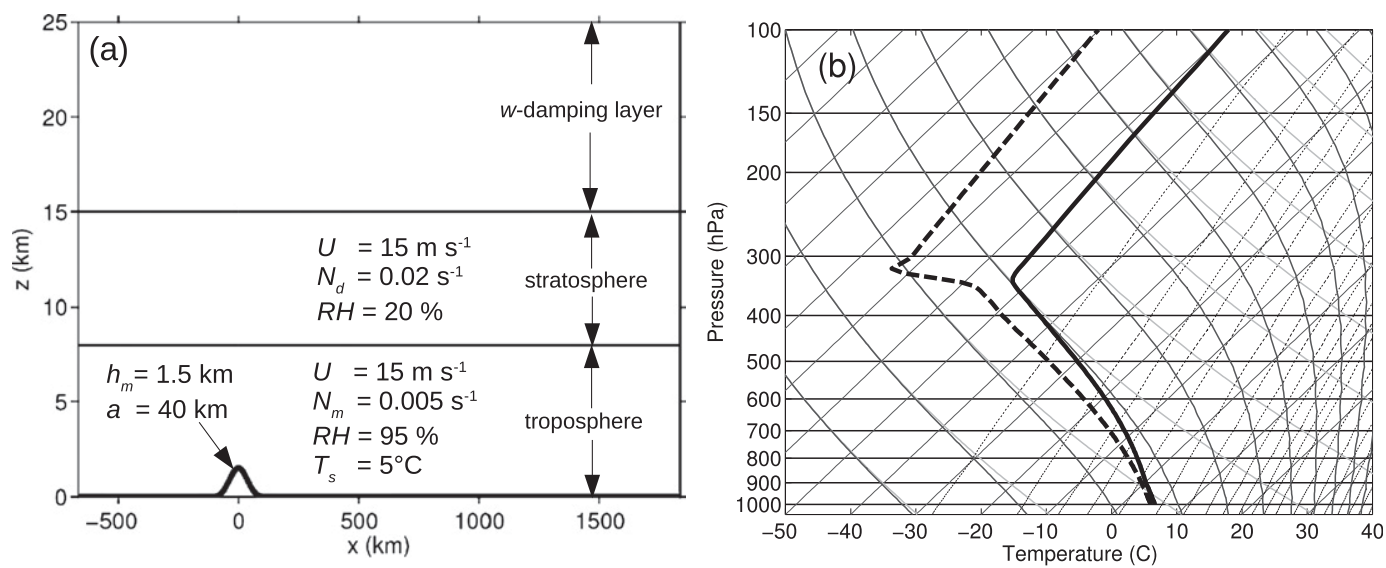

FIG. 3. Setup for the WRF simulations. (a) Model domain showing the control terrain profile with a thick line. The location of the troposphere, stratosphere, and damping layer are denoted, as are the initial atmospheric conditions for the control simulation; (b) Skew $T$ - $\log p$ plot showing soundings of temperature (solid) and dewpoint (dashed) used to initialize the control simulation.

2009). A positive-definite limiter (Skamarock and Weisman 2009) is applied during the advection of microphysical variables to eliminate spurious moisture sources that can bias precipitation simulations (e.g., Hahn and Mass 2009; Lin and Colle 2009).

Turbulent mixing is parameterized using a prognostic equation for turbulent kinetic energy, which determines eddy viscosities. Cumulus convection is presumed to be resolved because of the fine grid used, and thus it is not parameterized. Parameterizations for boundary layer mixing, land surface processes, and radiation are all omitted.

Before analysis, hourly output from WRF is linearly interpolated from the model's terrain-following coordinate onto a regularly spaced Cartesian grid. Results presented are 6-h averages beginning after the simulations reach an approximate steady state (at $42 \mathrm{~h}$ or later). Since the open upwind boundary condition does not mandate a steady incoming flow field, some modest drift occurs in the upwind conditions (e.g., $|\Delta U| \leq 0.3 \mathrm{~m} \mathrm{~s}^{-1},\left|\Delta T_{S}\right| \leq$ $0.3^{\circ} \mathrm{C},\left|\Delta N_{m}\right| \leq 0.0003 \mathrm{~s}^{-1}$ ). (This drift has only a modest influence on $Z_{S}$; however, results in Figs. 13-18 reference the upwind conditions during the analysis period instead of the initial conditions to account for this drift.)

\section{Results: Physical mechanisms}

Results from a control simulation are now presented and analyzed in detail to diagnose and quantify the physical mechanisms that control $Z_{S}$ on the mesoscale.

\section{a. Control simulation}

For the control simulation, the initial sounding is characterized by a troposphere with vertically uniform wind $U$ of $15 \mathrm{~m} \mathrm{~s}^{-1}, T_{s}$ of $5^{\circ} \mathrm{C}, N_{m}$ of $0.005 \mathrm{~s}^{-1}$, and $\mathrm{RH}$ of $95 \%$ (Fig. 3a). A skew $T-\log p$ plot of the control sounding is shown in Fig. $3 \mathrm{~b}$. The upwind $Z_{0 \mathrm{C}}$ of this sounding is about $880 \mathrm{~m}$. Sounding parameters were chosen such that the moist nondimensional mountain height $\left(N_{m} h_{m}\right) / U$ is 0.5 , small enough that the flow should be unblocked and rise over the barrier (Pierrehumbert and Wyman 1985; Jiang 2003; Galewsky 2008). The Rossby number $U /(f a)$ is 3.75 , indicating that rotational effects will play a modest role. The Coriolis force will act to limit the upwind influence of the topography to roughly a deformation radius $\left(N_{m} h_{m}\right) / f=75 \mathrm{~km}$ (Pierrehumbert and Wyman 1985).

Steady-state winds and cloud water fields from the control simulation are shown in Fig. 4. Cross-mountain winds $u$ are decelerated as the flow approaches the barrier, and along-mountain flow $v$ develops as the winds are turned to the left because of the decreased Coriolis force (Fig. 4a). The $u$ winds are everywhere positive, indicating that all flow passes over the ridge. The lack of surface friction allows strong near-surface winds $\left(>20 \mathrm{~m} \mathrm{~s}^{-1}\right.$ over the crest) to develop. Ascent over the mountain produces vertical winds $w$ exceeding $35 \mathrm{~cm} \mathrm{~s}^{-1}$ (Fig. 4b).

This vertical motion leads to supersaturation and condensation of cloud through a 4-km-deep region, apparent in the cloud water mixing ratio $q_{c}$ plotted in Fig. $4 \mathrm{~b}$. Cloud ice $q_{i}$ is generated above $z=5 \mathrm{~km}$ and grows by deposition to form snow $q_{s}$ (Fig. 5a). Below about $2 \mathrm{~km}$, high $q_{c}$ leads to riming of snow to form graupel $q_{g}$. At low levels the snow and graupel melt to form rain $q_{r}$. The surface precipitation rates, shown in Fig. 5b, reveal that the transition from rain to mostly snow with some graupel occurs over a few hundred meters of elevation and less 

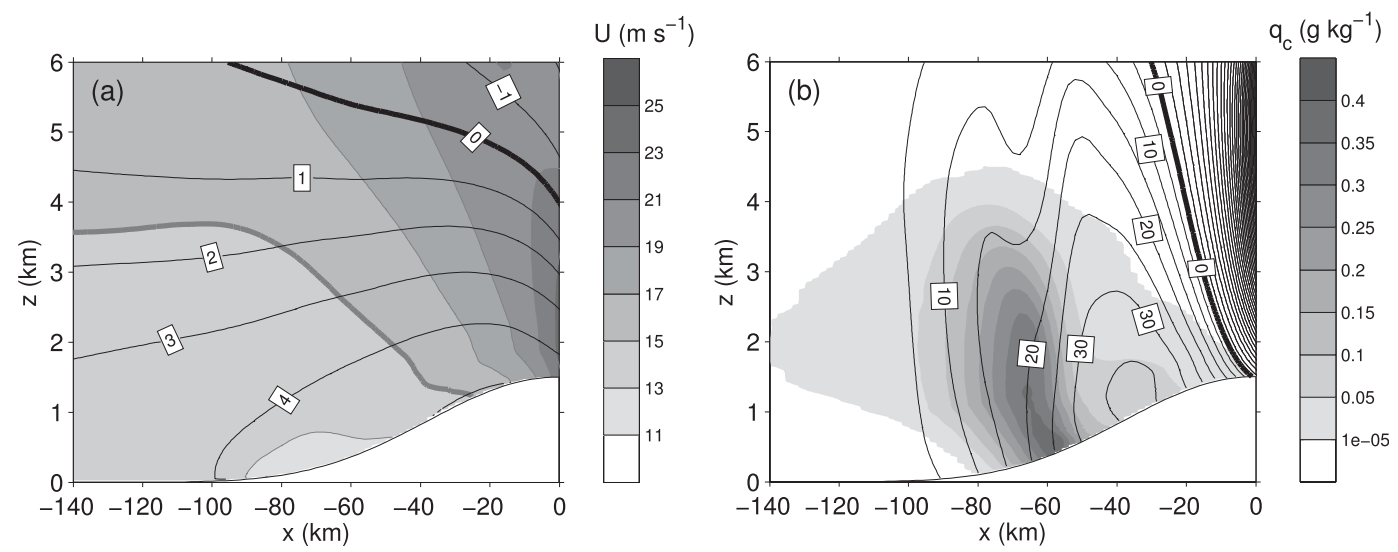

FIG. 4. Wind and cloud for control simulation. (a) Cross-mountain winds (shaded, with thick gray line at $u=U=$ $15 \mathrm{~m} \mathrm{~s}^{-1}$ ) and along-mountain winds (contoured every $1 \mathrm{~m} \mathrm{~s}^{-1}$, with thick line at $v=0$ ). (b) Vertical winds (contoured every $5 \mathrm{~cm} \mathrm{~s}^{-1}$, with thick line at $\left.w=0\right)$ and cloud liquid water mixing ratio $\left(q_{c}\right.$, shaded).

than $20-\mathrm{km}$ horizontal distance. The melting layer is detailed in Fig. 6, which shows that $Z_{0 \mathrm{C}}$ and $Z_{S}$ descend as the air approaches the terrain. Quantitatively, the mesoscale modifications of $Z_{S}$ and $Z_{0 \mathrm{C}}$ are $\delta_{0 \mathrm{C}}=142 \mathrm{~m}$, $\delta_{S}=221 \mathrm{~m}$, and $\delta=267 \mathrm{~m}$.

These basic results are only weakly sensitive to model horizontal and vertical resolution. For example, simulations with $\Delta x=6,18$, and $32 \mathrm{~km}$ (but maintaining the mountain's full height) yield $\delta$ values within $15 \%$ of the control value, and a simulation with only 91 vertical levels $(\Delta x \sim 40 \mathrm{~m}$ near the surface $)$ yields a $\delta$ value within $8 \%$ of the control.

Figure 6 offers some initial insights into the mechanisms. Isotherms in a deep layer descend toward the mountain. Since this descent occurs well away from the melting region, where air parcels have not been cooled by $Q_{\text {melt }}$, it is clear that another process-such as $Q_{\text {ad }}$ is playing a role in lowering $Z_{0 \mathrm{C}}$. Furthermore, the lack of a substantial modification of the temperature structure below $Z_{0 \mathrm{C}}$ (e.g., the lack of a near-isothermal layer) also suggests that $Q_{\text {melt }}$ is not pronounced. Also of note is the much larger drop in $Z_{S}$ as compared to $Z_{0 C}$, indicating the importance of $D_{\text {melt }}$ variations.

The following subsections further analyze the results of this simulation to characterize the contributions to $\delta$ of $Q_{\text {melt }}, Q_{\text {ad }}$, and $D_{\text {melt }}$. As illustrated schematically in Fig. 7, these will be quantified in such a way that their sum will equal the full $\delta$ :
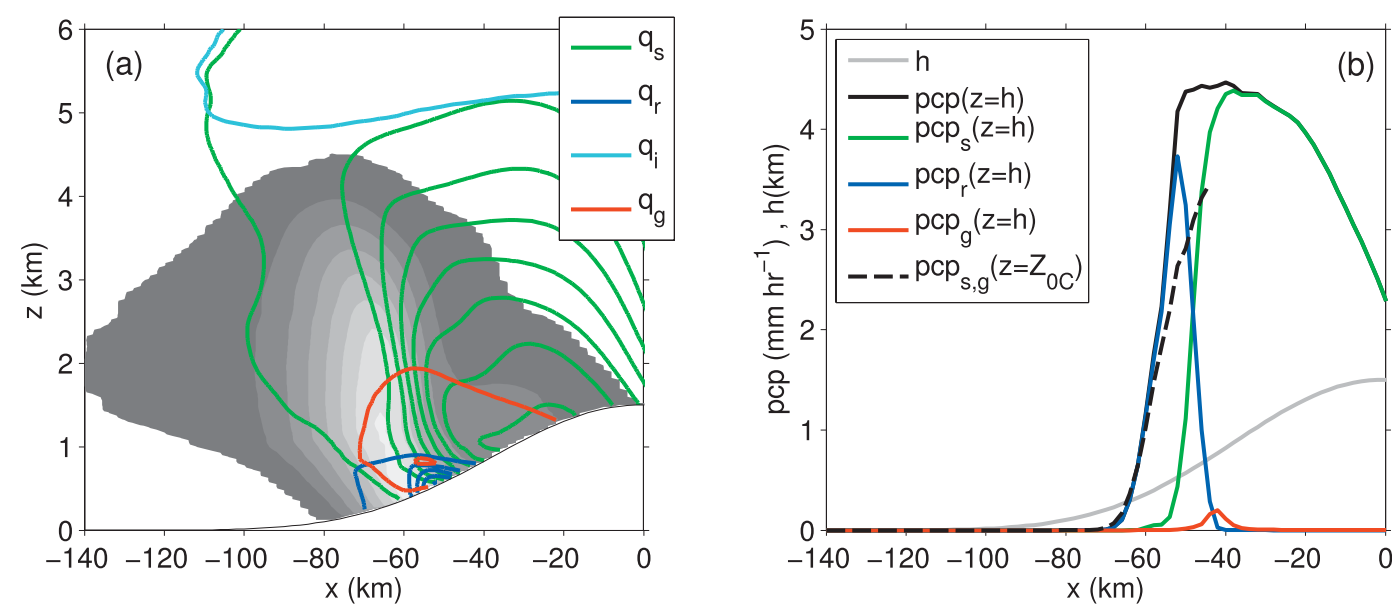

FIG. 5. (a) Mixing ratios of cloud and hydrometeor species for control simulation; $q_{c}$ is shaded every $0.05 \mathrm{~g} \mathrm{~kg}^{-1}$, starting at $1 \times 10^{-5} \mathrm{~g} \mathrm{~kg}^{-1}$. Hydrometeor mixing ratios are contoured every $0.1 \mathrm{~g} \mathrm{~kg}^{-1}$, starting at $1 \times 10^{-3} \mathrm{~g} \mathrm{~kg}^{-1}$ : rain $\left(q_{r}\right.$, blue), snow $\left(q_{s}\right.$, green), graupel $\left(q_{g}\right.$, red), and cloud ice $\left(q_{i}\right.$, cyan). (b) Surface precipitation rates (at $\left.z=h\right)$ for total precipitation $(\mathrm{pcp})$, rain $\left(\mathrm{pcp}_{r}\right)$, snow $\left(\mathrm{pcp}_{s}\right)$, and graupel $\left(\mathrm{pcp}_{g}\right)$. Also shown are the frozen precipitation rate $\left(\mathrm{pcp}_{s, g}\right)$ at $z=Z_{0 \mathrm{C}}$ and the terrain profile ( $h$, gray). 


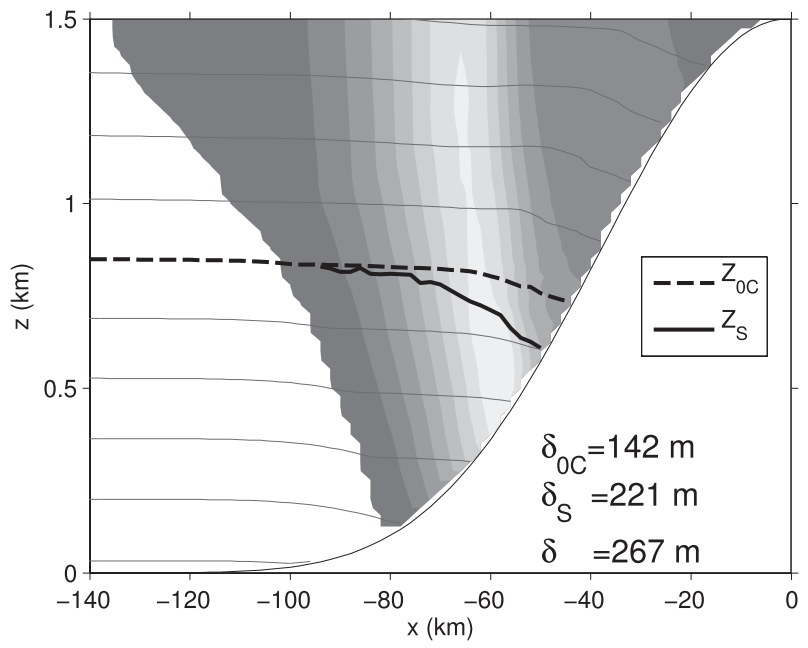

FIG. 6. Detail of melting region. Isotherms are contoured with thin lines every $1^{\circ} \mathrm{C}$. Also shown are $Z_{0 \mathrm{C}}$ (thick dashed line), $Z_{S}$ (thick solid line), and $q_{c}$ (shaded, as in Fig. 5a). The mesoscale modification of $Z_{0 \mathrm{C}}$ and $Z_{S}$ are noted $\left(\delta_{0 \mathrm{C}}, \delta_{S}\right.$, and $\left.\delta\right)$.

$$
\delta=(\delta)_{D_{\text {melt }}}+(\delta)_{Q_{\text {melt }}}+(\delta)_{Q_{\mathrm{ad}}}
$$

\section{b. Effect of microphysical melting distance}

The contribution of spatial variations in frozen hydrometeor melting distance $(\delta)_{D_{\text {melt }}}$ will be quantified first. Profiles through the melting layer of hydrometeor mixing ratios, taken at $x=-60 \mathrm{~m}$, are shown in Fig. 8 (solid lines). These show how $q_{s, g}$ decreases with distance below $Z_{0 \mathrm{C}}$. The vertical structure is similar to that produced by more detailed models of melting layer microphysics (e.g., Szyrmer and Zawadzki 1999).

Let us hypothesize that, for a given environmental profile, the essential processes determining $D_{\text {melt }}$ are the rates of sedimentation and melting of hydrometeors as determined by the precipitation rate at $Z_{0 \mathrm{C}}$ and by the mean vertical wind and temperature lapse rate below. This implies that other microphysical tendencies (e.g., collection, sublimation/deposition) and other environmental conditions (e.g., the mixing ratios of cloud ice and liquid water) are only of secondary importance in setting $D_{\text {melt }}$.

To test this hypothesis, a model of the precipitation in a single column of the melting layer is constructed. Hydrometeor mixing ratios $q_{s}, q_{g}$, and $q_{r}$ are stepped forward in time using a simplified version of the Thompson et al. (2008) scheme. This simplified scheme is formulated as described in Thompson et al. (2008) and configured in WRF V3.0.1, except that 1) all microphysical tendencies are ignored except sedimentation and melting; 2) an exponential size distribution for

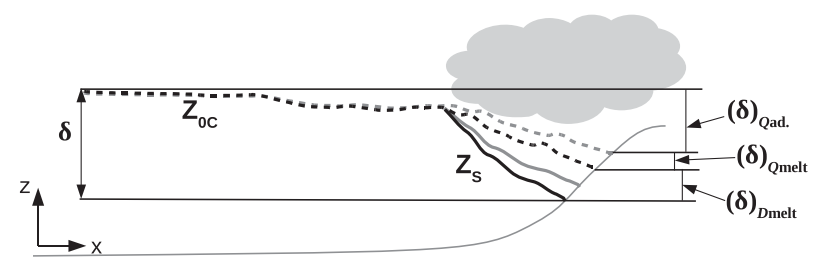

FIG. 7. Schematic diagram showing how the contributions of various physical processes to $\delta$ are quantified in the WRF simulation. Thick black lines represent $Z_{0 C}$ (dashed) and $Z_{S}$ (solid) from a control simulation, while thick gray lines represent $Z_{0 \mathrm{C}}$ and $Z_{S}$ from a simulation where $Q_{\text {melt }}$ is suppressed. Denoted on the right are contributions from $D_{\text {melt }}\left[(\delta)_{D_{\text {melt }}}\right], Q_{\text {melt }}\left[(\delta)_{Q_{\text {melt }}}\right]$, and $Q_{\text {ad }}\left[(\delta)_{Q_{\text {ad }}}\right]$.

snow is assumed (as in Thompson et al. 2004) instead of the generalized gamma distribution (as in WRF and Thompson et al. 2008); and 3) the "boosting" of snow terminal velocity based on diagnosed degree of riming is omitted. The spatial domain ranges from $Z_{0 \mathrm{C}}$ to the surface, and the vertical grid spacing is $10 \mathrm{~m}$. The temperature profile is assumed to be steady in time and is prescribed using the mean lapse rate from the output of the control WRF run at $x=-60 \mathrm{~m}\left(\Gamma=5.9^{\circ} \mathrm{C} \mathrm{km}^{-1}\right)$.

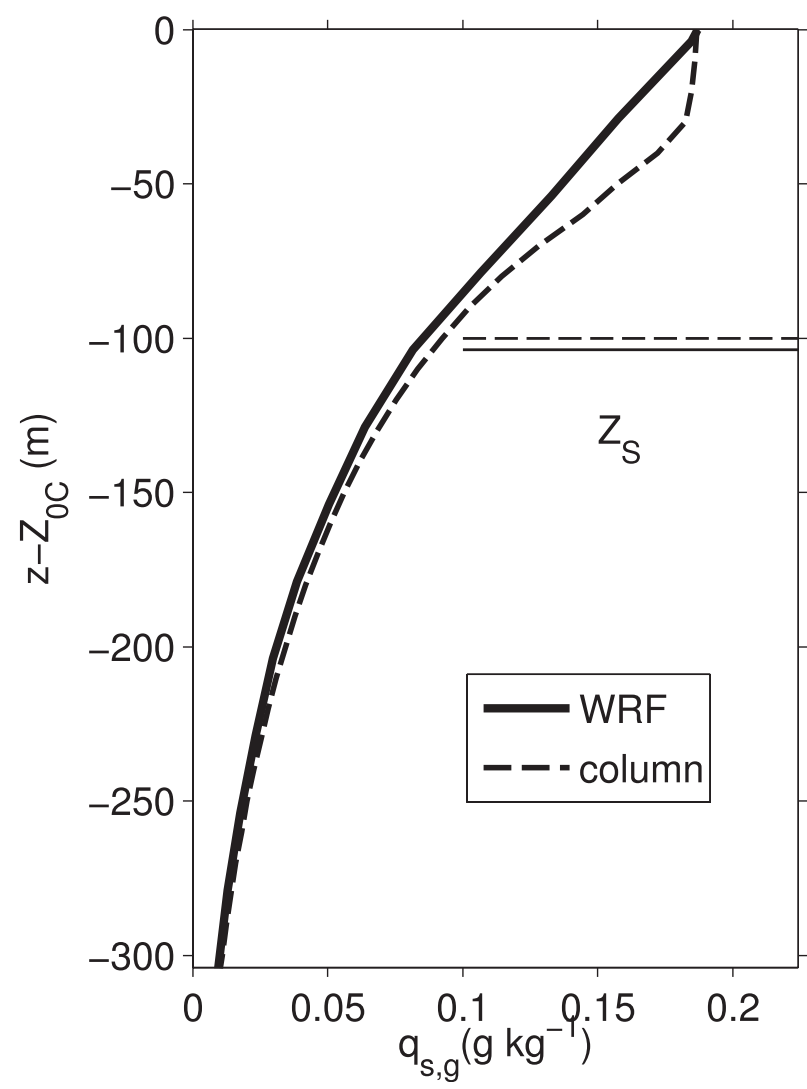

FIG. 8. Profiles of $q_{s, g}$ at $x=-60 \mathrm{~km}$ from WRF control simulation (solid) and simplified column model (dashed) as a function of distance below $Z_{0 \mathrm{C}}$. Horizontal lines show the $Z_{S}$ associated with the two $q_{s, g}$ profiles. 


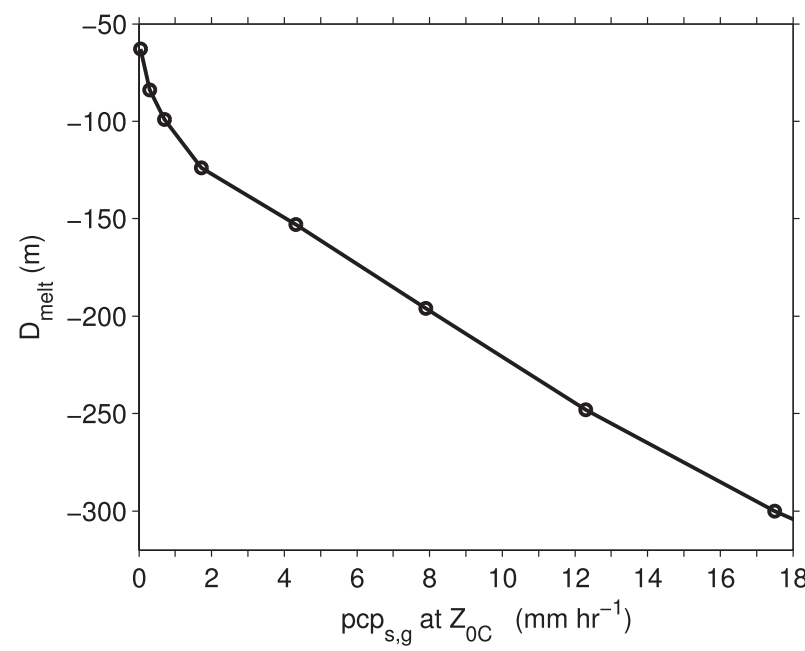

FIG. 9. Sensitivity of column model $D_{\text {melt }}$ to variations in $\mathrm{pcp}_{s, g}$ $\left(=\mathrm{pcp}_{s}+\mathrm{pcp}_{g}\right)$ at $Z_{0 \mathrm{C}}$. All simulations use the same lapse rate and $w$ as in Fig. 8.

The air is assumed to be saturated with respect to liquid water, and a uniform vertical velocity averaged from the WRF simulation $\left(w=0.24 \mathrm{~m} \mathrm{~s}^{-1}\right)$ is prescribed. The initial condition is zero hydrometeor mixing ratios, except at the upper boundary where the values from the WRF simulation are prescribed and held constant. The model is run to a steady state.

Results are plotted in Fig. 8 (dashed lines). The column model and WRF profiles of $q_{s, g}$ match well, as do the predicted values of $Z_{S}$. These results support the hypothesis that, at least over the middle of the windward slopes, $D_{\text {melt }}$ is determined mainly by the precipitation atop the melting layer and gross environmental characteristics within.

To illustrate the sensitivity of $D_{\text {melt }}$ to precipitation rate, the column model is applied again, using the same environmental conditions (i.e., $w, \Gamma$ ) but various mixing ratios, and hence precipitation rates, prescribed at $Z_{0 \mathrm{C}}$. Figure 9 shows that for very weak precipitation $D_{\text {melt }}$ is about $60 \mathrm{~m}$, but, as precipitation increases, $D_{\text {melt }}$ reaches beyond $300 \mathrm{~m}$. Where $Z_{S}$ intersects the terrain in the WRF simulation, $D_{\text {melt }}$ is $148 \mathrm{~m}$ (Fig. 6) and the frozen precipitation rate at $Z_{0 \mathrm{C}}$ is $3.5 \mathrm{~mm} \mathrm{~h}^{-1}$ (Fig. 5b). The column model predicts a very similar $D_{\text {melt }}(144 \mathrm{~m})$ for the same precipitation rate (Fig. 9). In WRF, $D_{\text {melt }}$ approaches zero at the upwind edge of the snowfall, where precipitation is very weak (at about $x=-90 \mathrm{~km}$ in Fig. 6). This contrasts with a $60-\mathrm{m} D_{\text {melt }}$ for weak precipitation in the column model (Fig. 9). This discrepancy may be due to the different size distribution assumptions in the column model and WRF.

The above comparisons of the column model and WRF suggest that, by modulating $D_{\text {melt }}$, spatial variations in orographic precipitation enhancement may contribute significantly to lowering $Z_{S}$ over the windward slopes. The component of $\delta$ attributable to $D_{\text {melt }}$ variations is quantified as $(\delta)_{D_{\text {melt }}}=\left(Z_{0 \mathrm{C}}\right)_{\mathrm{mtn}}-\left(Z_{S}\right)_{\mathrm{mtn}}$, where the subscript mtn signifies that mountainside values are used. This is shown schematically in Fig. 7. Note that the geometry of the rising terrain means that $Z_{S}$ intersects the terrain upwind of $Z_{0 \mathrm{C}}$. This limits the impact of cooling near the mountain, since lowering of $Z_{0 C}$ downwind of the mountainside $Z_{S}$ has no impact on $\delta$ or $\delta_{S}$. As defined, $(\delta)_{D_{\text {melt }}}$ includes this geometrical effect. For the control WRF simulation $(\delta)_{D_{\text {melt }}}=125 \mathrm{~m}$.

\section{c. Effect of latent cooling}

To quantify the role of melting-induced cooling $(\delta)_{Q_{\text {melt }}}$, another WRF simulation is conducted, the same as the control except that the absorption of latent heat by melting of precipitation is removed from the model's thermodynamic equation. Figure 10a compares $Z_{0 \mathrm{C}}$ and $Z_{S}$ from this "no $Q_{\text {melt }}$ " simulation and the control simulation, illustrating that $\delta_{0 \mathrm{C}}$ is reduced to $81 \mathrm{~m}$ (a reduction of $43 \%$ ) while $\delta_{s}$ is reduced to $190 \mathrm{~m}$ (a reduction of only $14 \%$ ). In this case, $Q_{\text {melt }}$ has an important impact on the structure of $Z_{0 \mathrm{C}}$, but a more modest impact on $Z_{S}$, since much of $\delta_{0 \mathrm{C}}$ occurs downwind of where $Z_{S}$ intersects the terrain (Fig. 10a). The component of $\delta$ attributable to $Q_{\text {melt }}$ is quantified as $(\delta)_{Q_{\text {melt }}}=$ $\delta_{0 \mathrm{C}}-\left(\delta_{0 \mathrm{C}}\right)_{\text {no } Q_{\text {melt }}}$ (Fig. 7). Since this definition focuses on the effects of $Q_{\text {melt }}$ on $Z_{0 \mathrm{C}}$ it overestimates the effect of $Q_{\text {melt }}$ on $Z_{S}$, since the lowering of $Z_{0 C}$ occurring downwind of the mountainside snow line does not affect $Z_{S}$. However, since this geometrical effect depends on the behavior of $Z_{S}$, it is included in $(\delta)_{D_{\text {melt }}}$. For the control WRF simulation $(\delta)_{Q_{\text {melt }}}=61 \mathrm{~m}$.

The modest contribution of $Q_{\text {melt }}$ is notable, since $Q_{\text {melt }}$ has been suggested as the principal cause for the lowering of $Z_{S}$ by several previous studies (e.g., Marwitz 1983, 1987; Colle 2004). Why is $Q_{\text {melt }}$ ineffective in substantially lowering $Z_{0 \mathrm{C}}$ and $Z_{S}$ in this simulation? An important time scale in the problem is the total time air parcels spend in the melting region, since this limits how much melting may cool the air. To characterize the residence time of air parcels in the melting region, 1-h back trajectories, calculated for air parcels ending at various locations along $Z_{0 \mathrm{C}}$, are plotted in Fig. 10b. Also plotted are $Z_{O C}$ and $q_{s, g}$, since only regions below $Z_{0 \mathrm{C}}$ with substantial $q_{s, g}$ should be associated with significant melting and cooling. The trajectories reveal that, because of the strong near-surface winds and the limited horizontal extent of the melting region, air parcels spend only about $10 \mathrm{~min}$ being cooled by melting. This is insufficient time for melting to cool the parcels substantially. Supporting this interpretation, application of 

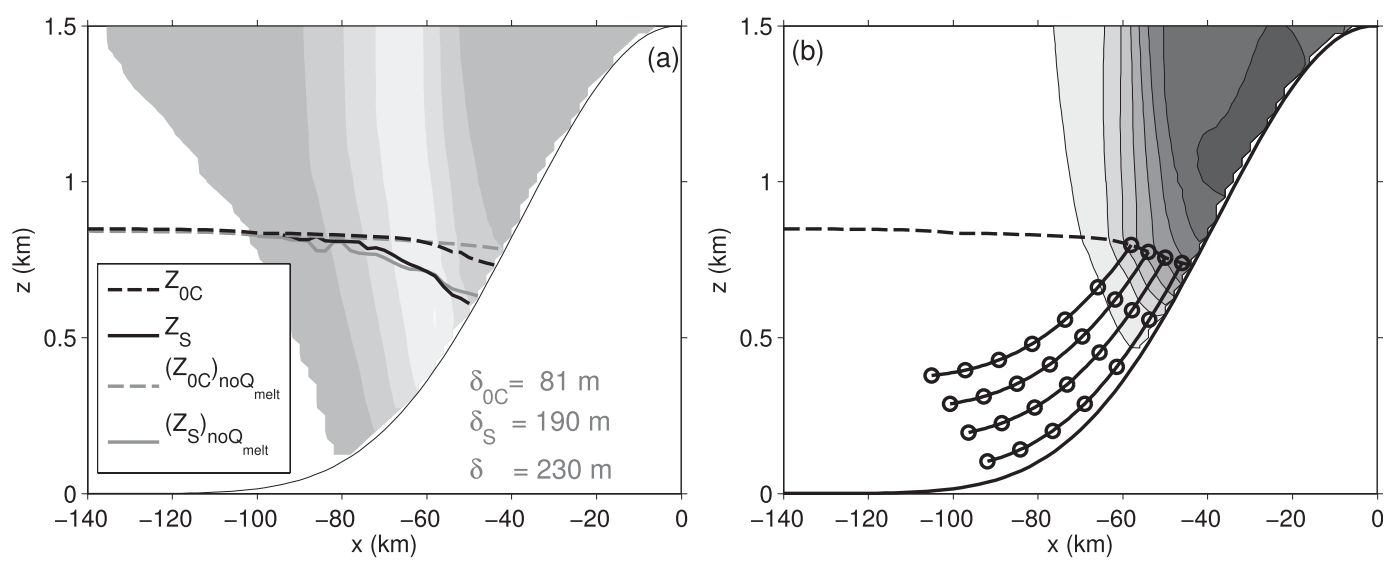

FIG. 10. (a) As in Fig. 6, but $Z_{0 \mathrm{C}}$ and $Z_{S}$ are also shown for the experiment in which $Q_{\text {melt }}$ is suppressed (dashed), and $\delta_{0 \mathrm{C}}, \delta_{S}$, and $\delta$ from the no- $Q_{\text {melt }}$ experiment are denoted. (b) Back-trajectory analysis for the control simulation. One-hour air parcel back trajectories ending at $Z_{0 \mathrm{C}}$ are plotted (solid black lines, with circles every $10 \mathrm{~min}$ ). Also shown are $q_{s, g}$ (shaded every $0.1 \mathrm{~g} \mathrm{~kg}^{-1}$, starting from $1 \times 10^{-5} \mathrm{~g} \mathrm{~kg}^{-1}$ ) and $Z_{0 \mathrm{C}}$ (dashed black line).

the simple model of Lin and Stewart (1986) [as modified by Unterstrasser and Zängl (2006)], using the environmental lapse rate and precipitation rate from the WRF simulation, predicts a very shallow $0^{\circ} \mathrm{C}$ layer of only $15 \mathrm{~m}$ when a 10-min precipitation duration is used.

\section{d. Effect of adiabatic cooling}

The contribution from adiabatic cooling $(\delta)_{Q_{\text {ad }}}$ is first examined by analyzing a model much simpler than the full WRF simulation: a Lagrangian air parcel model that describes the temperature of the near-surface air as it passes over the windward slopes of the mountain. This model assumes flow over the barrier is steady-state, pseudoadiabatic, unblocked, and laminar. In this scenario the lowest streamline parallels the topography (Fig. 11a), and parcel temperatures along this streamline are determined completely by the initial temperature and humidity of the air, and the amount of ascent that occurs; this is in turn determined by a the dry adiabatic lapse rate $\Gamma_{d}$ until saturation occurs, and thereafter by the moist pseudoadiabatic lapse rate $\Gamma_{m}$ (Fig. 11b). Thus, if the surface humidity and temperature upwind of the mountain are known, then the mountainside value of $Z_{0 \mathrm{C}}$ can be determined (Fig. 11b). ${ }^{3}$ If the upwind environmental temperature profile, and thus the upwind value of $Z_{0 \mathrm{C}}$, is also known (e.g., by knowledge of $N_{m}$ ), then $\delta_{0 \mathrm{C}}$ can be determined as well (Fig. 11b).

This simple parcel model can be used to understand how upwind stratification and temperature affect $\delta_{0 \mathrm{C}}$. First, note that, as long as the environmental lapse rate $\Gamma$

\footnotetext{
${ }^{3}$ This also assumes that the mountain is tall enough to lift and cool parcels to $0^{\circ} \mathrm{C}$.
}

is less than $\Gamma_{m}$ and $\Gamma_{d}$, a parcel rising over the mountain reaches $Z_{0 \mathrm{C}}$ at an elevation lower than the upwind sounding, and $Q_{\mathrm{ad}}$ acts to lower $Z_{0 \mathrm{C}}$. For cooler temperatures, adiabatic cooling should lower $Z_{0 \mathrm{C}}$ less, since parcel and environmental temperatures diverge less before reaching $0^{\circ} \mathrm{C}$ (Fig. 11c). Likewise, larger $\Gamma$ (smaller $N_{m}$ ) should lead to decreased lowering of $Z_{0 \mathrm{C}}$, since parcel and environmental temperatures diverge less quickly (Fig. 11d).

Values of $\delta_{0 \mathrm{C}}$ calculated with the parcel model are shown for a range of $T_{s}$ and $N_{m}$ in Fig. 12. This shows that $\delta_{0 \mathrm{C}}$ is positive everywhere except at very low values of $N_{m}^{2}$ and high values of $T_{s}$, since these correspond to environmental lapse rates larger than the moist pseudoadiabatic value [e.g., if $N_{m}=0$ and $d q_{w} / d x<0$, Eq. (1) implies $\Gamma>\Gamma_{m}$. Also, as predicted, there is a monotonic increase in $\delta_{0 \mathrm{C}}$ for increases in $T_{s}$ and $N_{m}^{2}$ (except at very low $N_{m}$ ). Note the large variations in $\delta_{0 \mathrm{C}}$ that occur due to changes in $T_{s}$ and $N_{m}{ }^{4}$

Revisiting the WRF results, the impact of $Q_{\text {ad }}$ is apparent at all elevations in the isotherms shown in Fig. 6. Ascent of unsaturated air parcels, upwind of the orographic cloud, results in a downward slope of isotherms since $\Gamma_{d}>\Gamma$. As the air reaches saturation at the edge of the cloud, condensation occurs, releasing latent heat, and air parcels begin to rise with lapse rate of $\Gamma_{m}$. This

\footnotetext{
${ }^{4}$ Note that the parcel model neglects blocking of the incoming airflow, which could prevent surface streamlines from following the topography, particularly for high mountains and strong stability. Therefore, the regime corresponding to the upper right of Fig. 12, where stabilities are high, a tall mountain is required to lift and cool parcels to $0^{\circ} \mathrm{C}$, and blocking is favored, is likely poorly represented by this model.
} 
(a)

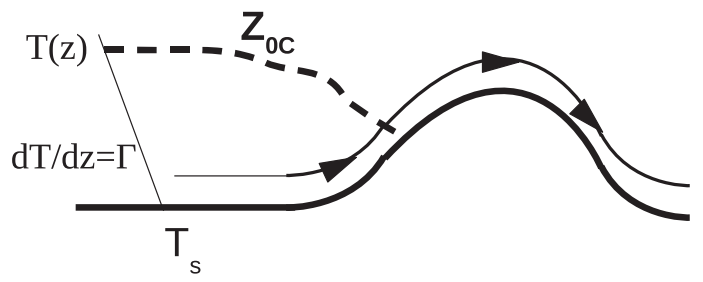

(c)

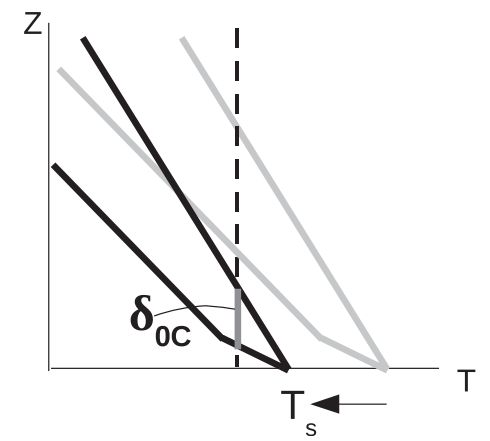

(b)

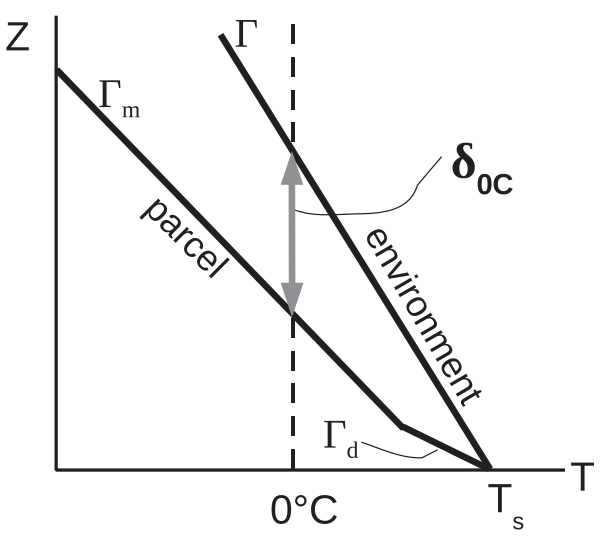

(d)

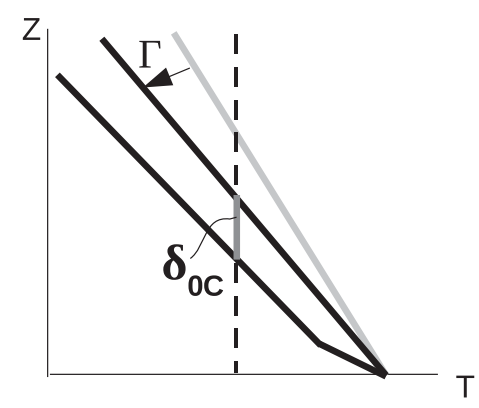

FIG. 11. Schematics showing how $\delta_{0 \mathrm{C}}$ is determined by $Q_{\text {ad }}$ in the parcel model. (a) $x-z$ section showing environmental temperature profile and flow along lowest streamline. (b) Idealized profiles of environmental temperature (with $\Gamma$ ) and parcel temperature (with $\Gamma_{d}$ and $\Gamma_{m}$ ), showing how lapse rate differences lead to $\delta_{0 \mathrm{C}}$. (c) Profiles showing how a decrease in $T_{s}$ decreases $\delta_{0 \mathrm{C}}$. (d) Profiles showing how an increase in $\Gamma$ (and decrease in $N_{m}$ ) decreases $\delta_{0 \mathrm{C}}$.

change in parcel lapse rate results in an abrupt change in the isotherm slope, but since $\Gamma_{m}$ is also greater than $\Gamma$, adiabatic cooling continues to force the isotherms to descend.

To relate the simple parcel model to the control WRF simulation, the $\delta_{0 \mathrm{C}}$ from the no- $Q_{\text {melt }}$ simulation is considered, since the parcel model does not attempt to account for $Q_{\text {melt }}$. For the upwind conditions associated with the WRF control simulation the parcel model predicts a $\delta_{0 \mathrm{C}}$ of $107 \mathrm{~m}$ (see gray circle in Fig. 12). This agrees fairly well with the $\delta_{0 \mathrm{C}}$ without $Q_{\text {melt }},\left(\delta_{0 \mathrm{C}}\right)_{\text {no }} Q_{\text {melt }}$, of $81 \mathrm{~m}$ from WRF. Thus, the portion of $\delta_{0 \mathrm{C}}$ not caused by $Q_{\text {melt }}$ appears to be almost entirely caused by $Q_{\text {ad }}$. Accordingly, the component of $\delta$ attributable to adiabatic cooling is quantified as $(\delta)_{Q_{\text {ad }}}=\left(\delta_{0 \mathrm{C}}\right)_{\text {no } Q_{\text {melt }}}$ (Fig. 7). Thus, $(\delta)_{Q_{\mathrm{ad}}}=81 \mathrm{~m}$ for the control simulation. Again, note that focusing on $Z_{0 \mathrm{C}}$ overestimates the effects of adiabatic cooling on $Z_{S}$ somewhat due to geometrical effects.

\section{Results: Sensitivity experiments}

To understand how mesoscale controls on $Z_{S}$ vary among different storms, climates, and mountain ranges a series of sensitivity experiments are conducted. In each experiment the same setup as the control simulation is used, but a single aspect of either the incoming flow or the terrain geometry is altered. Since airflow and

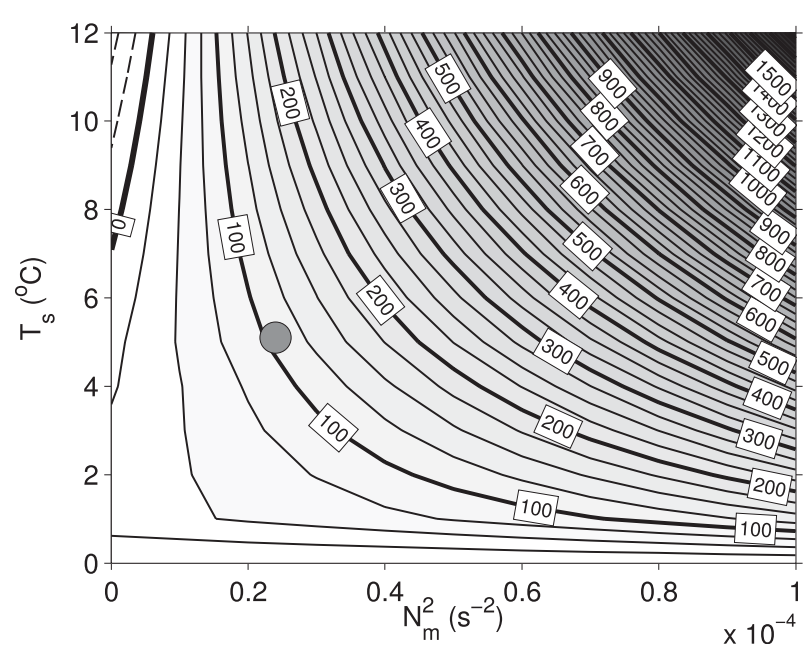

FIG. 12. Results from idealized parcel model showing $\delta_{0 \mathrm{C}}$ (contoured every $25 \mathrm{~m}$ ) as a function of $T_{s}$ and $N_{m}^{2}$ for $\mathrm{RH}=95 \%$. Negative contours are dashed. Gray circle shows the parameters used for the control WRF simulation. 

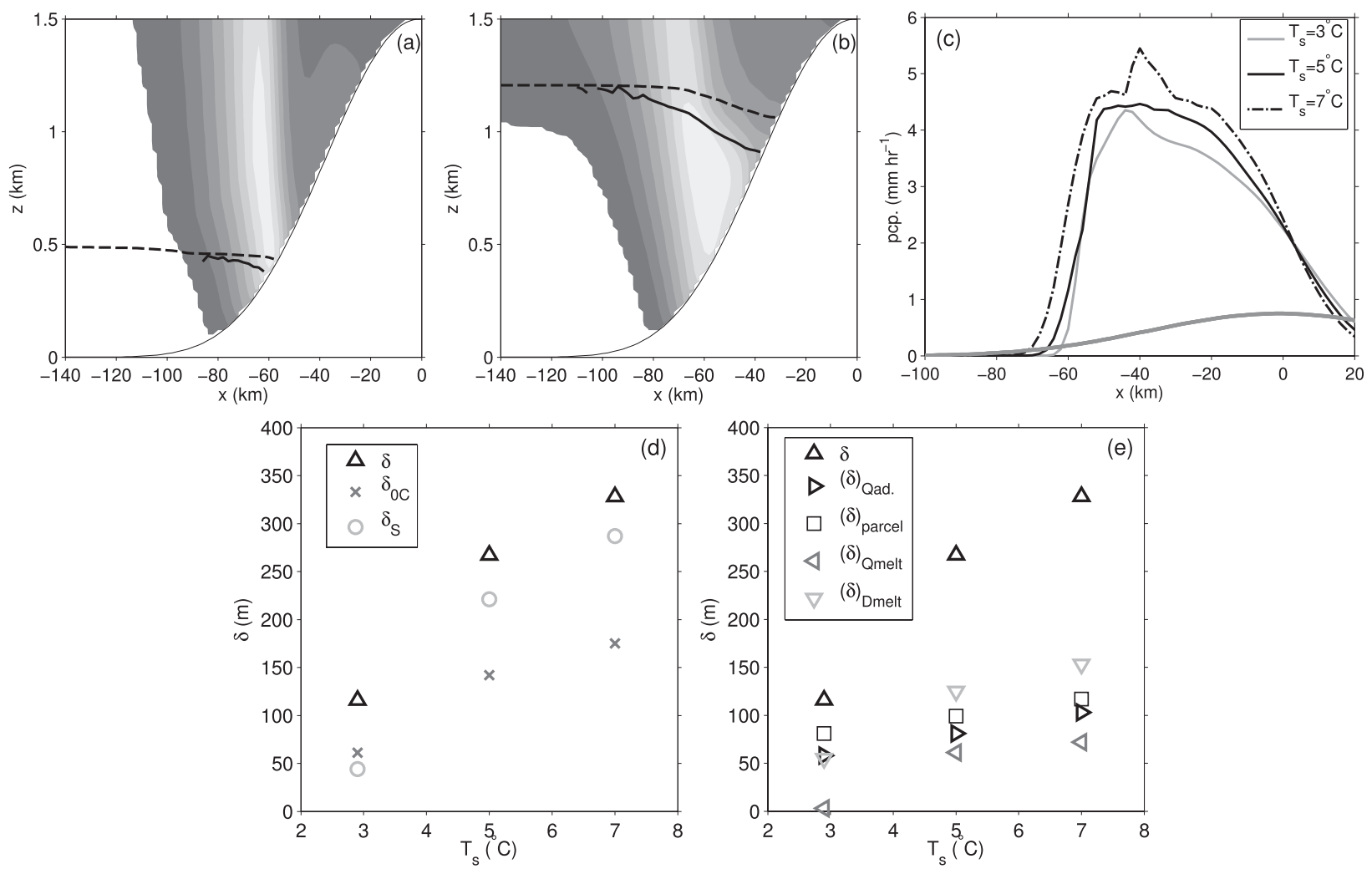

FIG. 13. Results from $T_{s}$ simulations. (a) Cross section for $T_{s}=3^{\circ} \mathrm{C}: q_{c}$ (shaded every $0.05 \mathrm{~g} \mathrm{~kg}^{-1}$ ), $Z_{0 \mathrm{C}}$ (dashed line), and $Z_{S}$ (solid line). (b) As in (a), but for $T_{s}=7^{\circ} \mathrm{C}$. (c) Surface precipitation rates (see key) and terrain profile (gray). (d) Values of $\delta_{S}, \delta_{0 \mathrm{C}}$, and $\delta$ as a function of $T_{s}$ (see key). (e) Contributions of $(\delta)_{D_{\text {melt }}},(\delta)_{Q_{\text {melt }}}$, and $(\delta)_{Q_{\text {ad }}}$ to $\delta$ as a function of $T_{s}$ (see key). Also included is the prediction of $(\delta)_{Q_{\text {ad }}}$ from $(\delta)_{\text {parcel }}$ (squares).

precipitation are most similar between $2 \mathrm{D}$ and 3D for unblocked flows (e.g., Epifanio and Durran 2001; Galewsky 2008), all but one of the following experiments are designed to keep $\left(N_{m} h_{m}\right) / U \leq 1$.

\section{a. Temperature}

To test sensitivity to temperature, additional simulations are made with warmer $\left(7^{\circ} \mathrm{C}\right)$ and colder $\left(3^{\circ} \mathrm{C}\right)$ values of $T_{s}$, with and without $Q_{\text {melt }}$. Figures 13a and 13b show cross sections with $q_{c}, Z_{0 \mathrm{C}}$, and $Z_{S}$ for these simulations. Since $N_{m}$ is held constant, the $T_{s}$ increase raises the upwind $Z_{0 \mathrm{C}}$ (from 0.50 to $1.24 \mathrm{~km}$ ). Figure $13 \mathrm{c}$ shows the surface precipitation rates (pcp). As $T_{s}$ is increased, pcp increases because of enhanced moisture flux, although this increase is moderated by microphysical effects (e.g., Kirshbaum and Smith 2008).

Figure $13 \mathrm{~d}$ shows that $\delta_{0 \mathrm{C}}, \delta_{S}$, and $\delta$ all increase with increasing $T_{s}$, and Fig. 13e quantifies the contributions to $\delta$ of $(\delta)_{D_{\text {melt }}},(\delta)_{Q_{\text {melt }}}$, and $(\delta)_{Q_{\text {ad }}}$. All three mechanisms act to increase $\delta$ with warming. Increased $Q_{\text {ad }}$ results from the higher $Z_{0 \mathrm{C}}$ (e.g., Figs. $11 \mathrm{c}$ and 12), while increased $(\delta)_{Q_{\text {melt }}}$ and $(\delta)_{D_{\text {melt }}}$ result from higher precipitation rates atop the melting layer. The impact of $Q_{\mathrm{ad}}$ predicted by the parcel model $(\delta)_{\text {parcel }}$ is also shown, and mimics the variations in $(\delta)_{Q_{a d}}$ from WRF (Fig. 13e). ${ }^{5}$

If a similar dependency of $\delta$ on $T_{s}$ exists in nature it could have important consequences for regional climate change in mountainous areas. As $T_{s}$ is warmed in these simulations, $Z_{0 \mathrm{C}}$ rises by $742 \mathrm{~m}$ upwind of the mountains. However, because of the increase in $\delta, Z_{S}$ only rises by $530 \mathrm{~m}$ on the mountainside. Thus, mesoscale processes over the mountain act to buffer the impact of warming on $Z_{S}$, reducing by $29 \%$ the rise in $Z_{S}$ that would be expected by only considering the effects of warming on the upwind $Z_{0 \mathrm{C}}$.

\section{b. Stratification}

To test the effect of stratification, simulations are made with smaller $\left(N_{m}=0.002 \mathrm{~s}^{-1}\right)$ and larger $\left(N_{m}=\right.$ $0.007 \mathrm{~s}^{-1}$ ) moist stabilities (Fig. 14). As $N_{m}$ is increased,

\footnotetext{
${ }^{5}$ This and subsequent $(\delta)_{\text {parcel }}$ calculations use the upwind $N_{m}$ and $T_{s}$ at the time of analysis to account for the modest drift that occurs in the upwind conditions.
} 

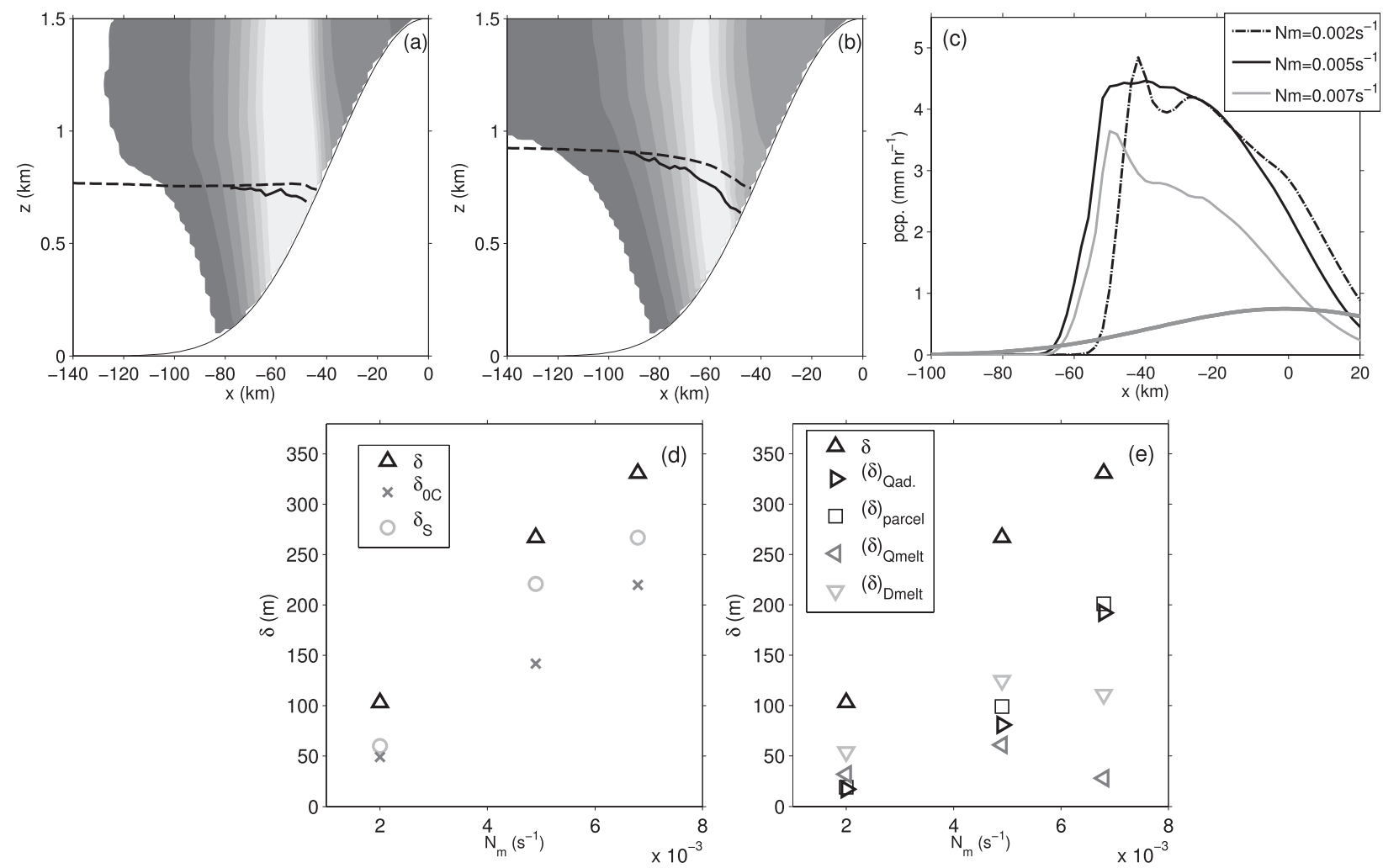

FIG. 14. (a) As in Fig. 13a, but for $N_{m}=0.002 \mathrm{~s}^{-1}$ simulation. (b) As in (a), but for $N_{m}=0.007 \mathrm{~s}^{-1}$. (c) As in Fig. $13 \mathrm{c}$, but for $N_{m}$ simulations. (d),(e) As in Figs. 13d,e, but for $N_{m}$ experiments.

the upwind $Z_{\mathrm{OC}}$ is increased since $\Gamma$ is decreased (Figs. 14a,b). Changes in $N_{m}$ affect both the upwind water vapor flux profile and the pattern of vertical motion over the mountain, and the effect on the precipitation pattern is complex (Fig. 14c). For instance, surface precipitation shifts upwind as $N_{m}$ increases from $=0.002$ to $0.005 \mathrm{~s}^{-1}$, due to a greater upwind tilt with height of the gravity wave vertical velocities (e.g., Smith and Barstad 2004; Colle 2004). However, further increases in $N_{m}$, from 0.005 to $0.007 \mathrm{~s}^{-1}$, result in gravity wave descent aloft that suppresses the formation of $q_{i}$ above the windward slope (not shown) and drastically reduces pcp over much of the mountain (Fig. 14c).

Figure $14 \mathrm{~d}$ shows that $\delta$ increases with $N_{m}$. This is largely attributable to increases in $\delta_{0 \mathrm{C}}$ due to $(\delta)_{O_{\text {ad }}}$, which are predicted well by the parcel model (Fig. $14 \mathrm{e}$ ). Changes in $(\delta)_{D_{\text {melt }}}$ and $(\delta)_{Q_{\text {melt }}}$ are more complex (in part due to the complex changes in pcp), reinforcing the $(\delta)_{Q_{a d}}$ changes at low $N_{m}$ and partially compensating for them at high $N_{m}$.

\section{c. Wind speed}

To test the effect of wind speed, simulations are made with slower $\left(U=10 \mathrm{~m} \mathrm{~s}^{-1}\right)$ and faster $\left(U=20 \mathrm{~m} \mathrm{~s}^{-1}\right)$ cross-mountain winds (Fig. 15). Since the moisture flux scales with $U$, changes in wind speed have a large impact on precipitation intensity, with stronger winds yielding heavier precipitation rates (Fig. 15c). Increasing $U$ from 10 to $15 \mathrm{~m} \mathrm{~s}^{-1}$ increases pcp everywhere. In contrast, as $U$ is increased further, to $20 \mathrm{~m} \mathrm{~s}^{-1}$, the time scale associated with cross-mountain advection becomes comparable with the microphysical time scales required for precipitation formation and fallout, resulting in a downwind shift of the pcp pattern (e.g., Jiang and Smith 2003; Smith and Barstad 2004; Colle 2004).

Increasing $U$ from 10 to $15 \mathrm{~m} \mathrm{~s}^{-1}$ increases $\delta_{0 \mathrm{C}}, \delta_{S}$, and $\delta$, while increasing $U$ from 15 to $20 \mathrm{~m} \mathrm{~s}^{-1}$ leads to declines (Figs. 15a,b,d). For $U=20 \mathrm{~m} \mathrm{~s}^{-1}, Z_{S}$ is not defined at some points near the mountain because strong updrafts keep all snow above $Z_{0 \mathrm{C}}$ (Fig. 15b).

The initial increase in $\delta$, from $U=10$ to $15 \mathrm{~m} \mathrm{~s}^{-1}$ is due to increases in $(\delta)_{Q_{\text {melt }}}$ and $(\delta)_{D_{\text {melt }}}$ associated with enhanced pcp (Fig. 15e). For these wind speeds, increased pcp causes $Q_{\text {melt }}$ to weakly increase with $U$ despite the decreased residence time of air parcels in the melting region. As $U$ is increased to $20 \mathrm{~m} \mathrm{~s}^{-1}$ the region of intense pcp in shifted downwind (away from the melting layer) and strong vertical winds loft melting snowflakes. These changes act to nearly eliminate $(\delta)_{D_{\text {melt }}}$. There is little $U$ dependence of $(\delta)_{Q_{\text {ad }}}$, as predicted by $(\delta)_{\text {parcel. }}$ 

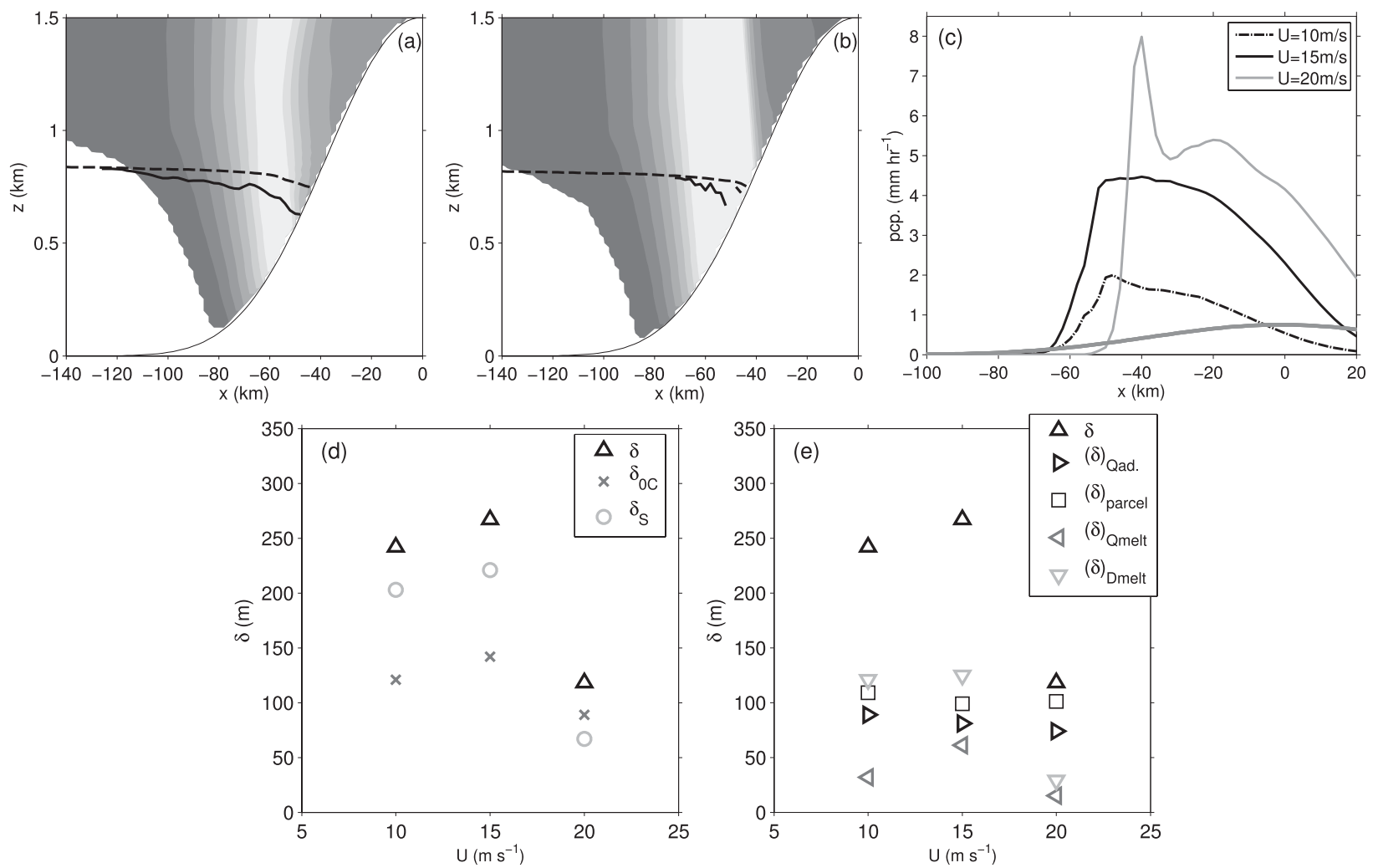

FIG. 15. (a) As in Fig. 13a, but for $U=10 \mathrm{~m} \mathrm{~s}^{-1}$ simulation. (b) As in (a), but for $U=20 \mathrm{~m} \mathrm{~s}^{-1}$. (c) As in Fig. 13c, but for $U$ simulations. (d),(e) As in Figs. 13d,e, but for $U$ experiments.

\section{d. Relative humidity}

To test the effect of humidity, simulations are made with $\mathrm{RH}$ ranging from $85 \%$ to $98 \%$ (Fig. 16). As $\mathrm{RH}$ is increased, both the intensity and extent of precipitation increase, since the moisture flux is increased and less lifting is required to cool the air to saturation (Fig. 16c).

Increasing RH leads to strong decreases in $\delta_{0 \mathrm{C}}$ and $\delta$, whereas $\delta_{S}$ is more weakly affected (Figs. 16a,b,d). Variations in $(\delta)_{Q_{\mathrm{ad}}}$ are responsible for most of the $\mathrm{RH}$ sensitivity (Fig. 16e). Decreasing RH increases $(\delta)_{Q_{\text {ad }}}$ because air parcels rise and cool dry adiabatically longer at lower $\mathrm{RH}$, resulting in larger lapse rate differences between parcel and upwind temperature profiles. This behavior is captured well by the parcel model (Fig. 16e). Both $(\delta)_{D_{\text {melt }}}$ and $(\delta)_{Q_{\text {melt }}}$ show some weak sensitivity to $\mathrm{RH}$ associated with pcp changes.

\section{e. Mountain width}

To test the effect of mountain width, simulations are made with $a$ ranging from 15 to $65 \mathrm{~km}$ (Fig. 17). As $a$ increases, precipitation becomes more broadly distributed and less intense (Fig. 17c). Although intensity decreases, the total precipitation over the windward slopes increases by about $50 \%$ as $a$ varies from 15 to $65 \mathrm{~km}$. This occurs because the increased time scale for cross-mountain advection (relative to microphysical conversion and sedimentation time scales) allows more water vapor to condense and fallout before being advected into the lee (e.g., Jiang and Smith 2003; Smith and Barstad 2004; Colle 2004).

Figures $17 \mathrm{a}, 17 \mathrm{~b}$, and $17 \mathrm{~d}$ show that $\delta_{S}, \delta_{0 \mathrm{C}}$, and $\delta$ all increase with $a$. This behavior comes from variations in $(\delta)_{D_{\text {melt }}}$ and $(\delta)_{Q_{\text {melt }}}$ (Fig. 17e). As the mountain becomes wider and less steep, decreased vertical velocities increase frozen hydrometeor fall speeds next to the mountain, providing larger $(\delta)_{D_{\text {melt }}}$. Also, as $a$ increases, the melting layer broadens in horizontal extent, and vertical velocities are reduced. Together these effects increase the residence time of air parcels in the melting layer and thus increase $(\delta)_{Q_{\text {melt }}}$. There is little change in $(\delta)_{Q_{\mathrm{ad}}}$ with $a$, as predicted by the parcel model.

\section{f. Mountain height}

To test the effect of mountain height, simulations are made with $h_{m}$ ranging from 1.2 to $3 \mathrm{~km}$ (Fig. 18). As the mountain becomes taller, precipitation becomes more 

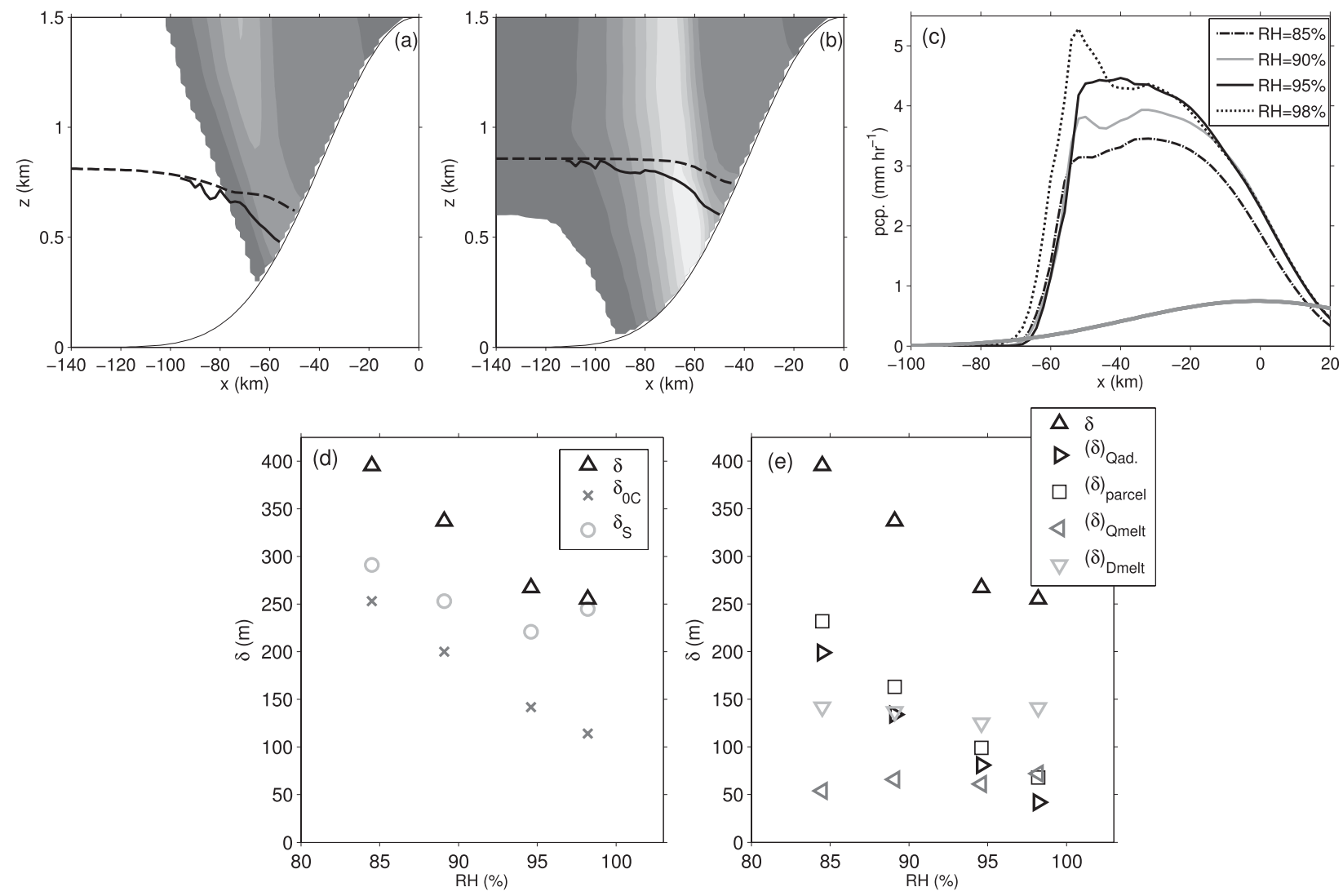

FIG. 16. (a) As in Fig. 13a, but for $\mathrm{RH}=85 \%$ simulation. (b) As in (a), but for $\mathrm{RH}=98 \%$. (c) As in Fig. 13c, but for RH simulations. (d),(e) As in Figs. 13d,e, but for RH experiments.

intense because of increased lifting of the incoming flow (Fig. 18c).

As $h_{m}$ is increased there is surprisingly little coherent change in $\delta_{S}, \delta_{0 \mathrm{C}}$, or $\delta$ (Fig. 18d). None of the three mechanisms shows a strong $h_{m}$ dependence (Fig. 18e). While increased precipitation rates should act to increase $(\delta)_{D_{\text {met }}}$ with $h_{m}$, increased $w$ in the melting layer appears to loft melting snow and keep $D_{\text {melt }}$ fairly constant. Similarly, increases in pcp should increase $(\delta)_{Q_{\text {melt }}}$, but decreased residence time in the melting layer due to increased $w$ appears largely to cancel this effect. For $h_{m}=1.2-2 \mathrm{~km}$, changes in $(\delta)_{Q_{\mathrm{ad}}}$ with $h_{m}$ are minimal, as predicted by the parcel model. For $h_{m}=2.5-3 \mathrm{~km}$, $(\delta)_{Q_{\text {ad }}}$ drops, well below $(\delta)_{\text {parcel. }}$ This may be due to low-level flow deceleration, which enhances vertical shear and the mixing down of potentially warmer air over the mountain slopes.

\section{g. A preliminary look at the effects of blocking}

The above experiments have avoided the blocked regime, where $2 \mathrm{D}$ simulations produce airflow and precipitation distinct from 3D simulations, even for very long ridges (Epifanio and Durran 2001; Galewsky
2008). As $\left(N_{m} h_{m}\right) / U$ increases, low-level flow deflection around mountains becomes substantial in 3D flows. This deflection reduces ascent over the terrain, moderates precipitation rates, and spreads precipitation upwind (e.g., Jiang 2003; Galewsky 2008). Since this flow deflection can only be properly represented in 3D simulations, the generalizability of 2D results in the blocked regime is questionable at best.

Nevertheless, a single 2D simulation in the blocked regime is conducted. This is used only as a tool to investigate qualitatively the effects of airflow deceleration and blocking on $Z_{S}$. The simulation is conducted with $h_{m}=3 \mathrm{~km}, N_{m}=0.005 \mathrm{~s}^{-1}$, and $U=10 \mathrm{~m} \mathrm{~s}^{-1}$. This gives $\left(N_{m} h_{m}\right) / U=1.5$, indicating favorable conditions for flow deceleration and splitting. Since the flow is more transient in this regime, results presented are averaged only over a 2-h period: $t=86-87 \mathrm{~h}$.

Results show that cross-mountain flow is severely decelerated over the lower windward slopes to less than $2 \mathrm{~m} \mathrm{~s}^{-1}$ (Fig. 19a). The flow deceleration is much stronger than that found in the $h_{m}=3 \mathrm{~km}$ case from the previous section (not shown) because of the decreased $U$ and consequently increased $\left(N_{m} h_{m}\right) / U$. The weak 

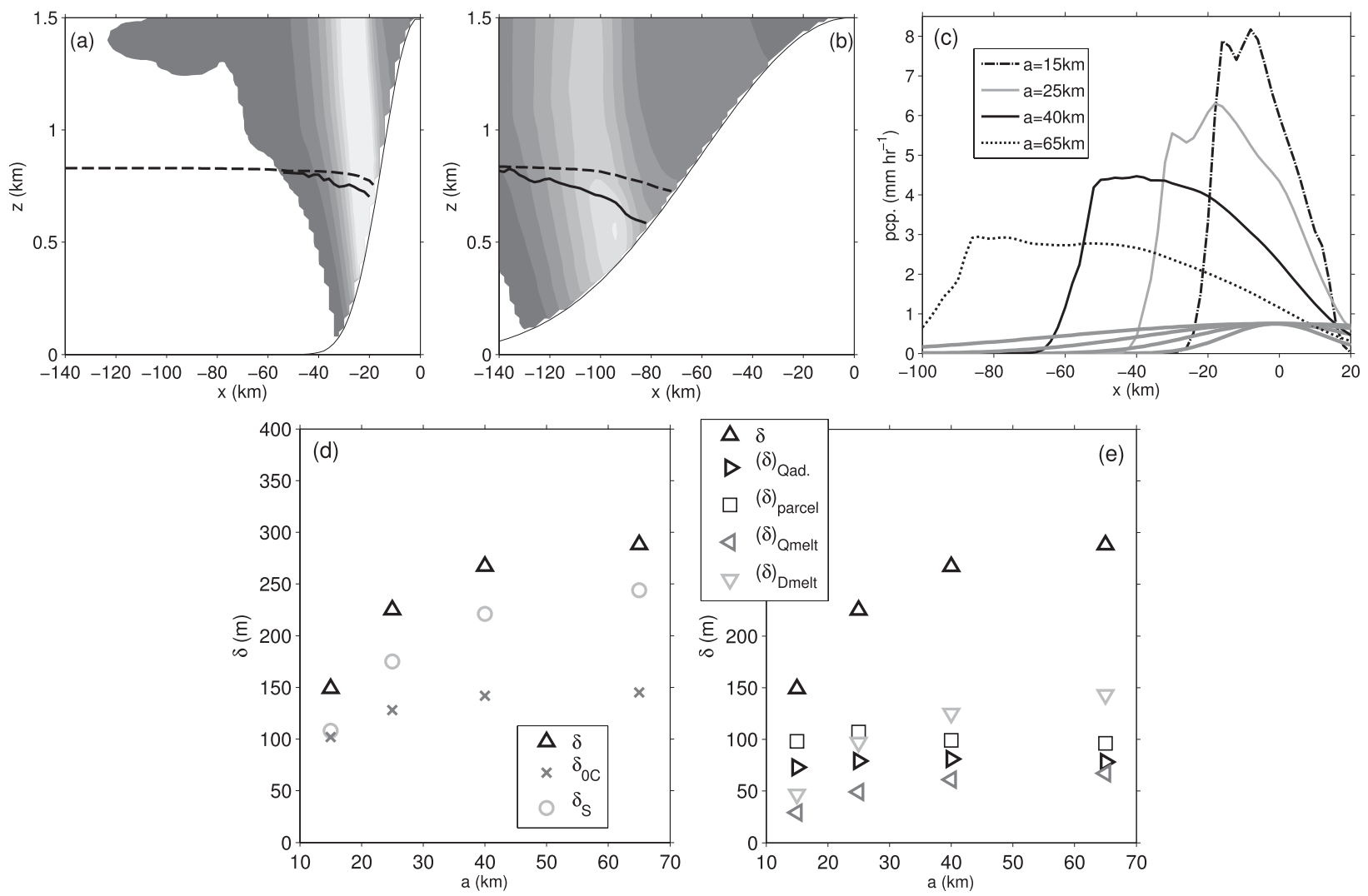

FIG. 17. (a) As in Fig. 13a, but for the $a=15 \mathrm{~km}$ simulation. (b) As in (a), but for $a=65 \mathrm{~km}$. (c) As in Fig. 13c, but for $a$ simulations. (d),(e) As in Figs. 13d,e, but for $a$ experiments.

low-level winds lead to large residence times for air parcels in the melting region, allowing for substantial $Q_{\text {melt }}$ that destroys the low-level stratification, and produces convective cells at the foot of the mountain with their tops in the melting layer (Findeisen 1940; Szyrmer and Zawadzki 1999). The role of melting in producing these cells is confirmed by examining a simulation without $Q_{\text {melt }}$, which exhibits no convection (Fig. 19b). Low-level flow deceleration also results in lifting, cloud, and precipitation far upwind of the mountain, and the convective overturning leads to localized maxima in the microphysical fields (Fig. 19c).

Figure $19 \mathrm{~d}$ shows that $Z_{S}$ and $Z_{0 \mathrm{C}}$ descend sharply in this simulation, dropping by about $50 \%$ more than in any of the previous experiments $(\delta=603 \mathrm{~m})$. Much of this descent is eliminated when $Q_{\text {melt }}$ is suppressed (Fig. 19d). Thus, cooling from melting, and the subsequent downward mixing of the cooled air by the induced convection, plays a crucial role in producing the large $\delta$ found in this case. While these results suggest that flow blocking and deceleration may enhance $(\delta)_{Q_{\text {mett }}}$ and produce large $\delta$, fully $3 \mathrm{D}$ simulations are required to more accurately quantify these effects.

\section{Results: Microphysical uncertainties}

An array of studies have documented how the simulated amount, pattern, and phase of orographic precipitation depends on the microphysical parameterization chosen and how it is applied (e.g., Colle and Zeng 2004a,b; Thompson et al. 2004; Colle et al. 2005; Grubišić et al. 2005; Lin and Colle 2009; Jankov et al. 2009). The impact of the microphysical scheme on these results is explored by repeating the control simulation using four other microphysical parameterizations available in WRF. All are bulk schemes-with assumed size distributions for precipitation and cloud particles-that predict cloud liquid water, cloud ice, rain, snow, and graupel separately. These include the default WRF v3.0.1 configurations of the following schemes: Purdue-Lin (Chen and Sun 2002), WRF single-moment six-phase (WSM6) (Hong et al. 2004; Hong and Lim 2006), the Goddard Cumulus Ensemble (Tao et al. 2003), and Morrison et al. (Morrison et al. 2005, 2009). Detailed discussions of the differences between these are found in Skamarock et al. (2008), Lin and Colle (2009), and Jankov et al. (2009). 

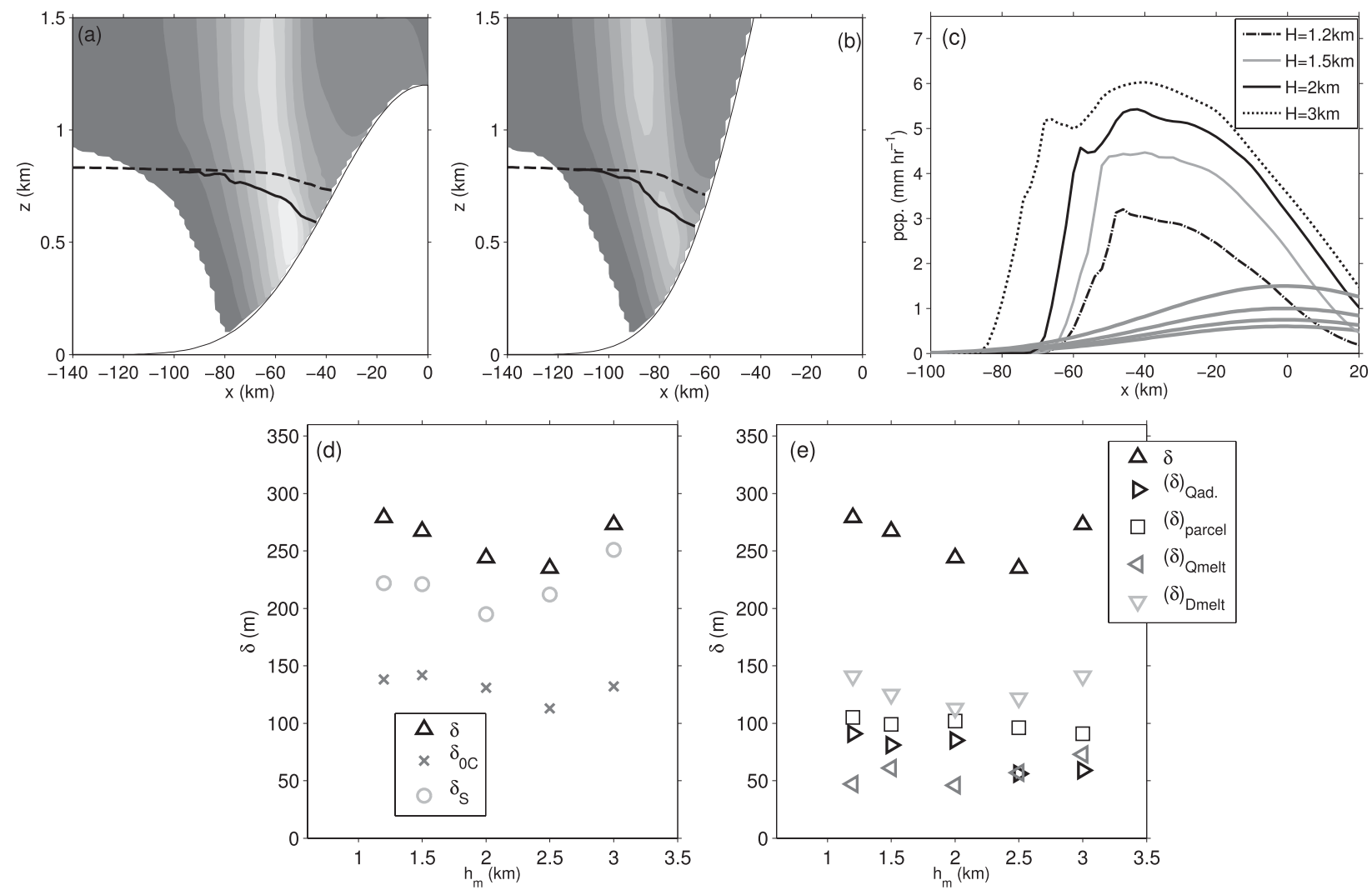

FIG. 18. (a) As in Fig. 13a, but for $h_{m}=1.2 \mathrm{~km}$. (b) As in (a), but for $h_{m}=3 \mathrm{~km}$. (c) As in Fig. 13c, but for $h_{m}$ simulations. (d),(e) As in Figs. 13d,e, but for $h_{m}$ experiments.

The top panels in Fig. 20 show how the predicted mixing ratios vary among the schemes. All of these schemes simulate more $q_{i}$ aloft as compared to Thompson et al. In the WSM6 simulation, $q_{c}$ is confined to much lower levels and shows a strong enhancement near $Z_{0 \mathrm{C}}$. Like Thompson et al., Goddard and WSM6 produce a mixture of snow and graupel, whereas Purdue-Lin produces nearly all graupel and Morrison et al. produces all snow. These differences in the relative abundance of $q_{s}$ and $q_{g}$ are consistent with the results of previous studies (e.g., Lin and Colle 2009; Jankov et al. 2009).

All the simulations exhibit a drop in both $Z_{0 \mathrm{C}}$ and $Z_{S}$ over the windward slopes (see bottom panels of Fig. 20). They produce a fairly similar $\delta_{0 \mathrm{C}}$ (all $\delta_{0 \mathrm{C}}$ values are within $27 \%$ of the mean $\delta_{0 \mathrm{C}}$ across the five schemes). Thus, it appears that $(\delta)_{Q_{\text {ad }}}$ and $(\delta)_{Q_{\text {melt }}}$, which act by lowering $Z_{0 \mathrm{C}}$, operate similarly regardless of the details of the microphysical scheme. This is perhaps unsurprising since these mechanisms depend mostly on airflow, thermodynamics, and gross aspects of the microphysics that are similar between the simulations.

The structure of $Z_{S}$ is much less consistent across the various runs. The Purdue-Lin and WSM6 simulations give substantially larger $\delta$ than the control simulation, but show a similar $Z_{S}$ structures to the control, with $D_{\text {melt }}$ increasing as the mountain is approached. In contrast, for both the Goddard and the Morrison et al. simulations $Z_{S}$ does not diverge from $Z_{0 \mathrm{C}}$ as the mountain is approached. ${ }^{6}$ Accordingly, in these cases $(\delta)_{D_{\text {melt }}}$ contributes little to $\delta$. Thus, in contrast to $(\delta)_{Q_{\mathrm{ad}}}$ and $(\delta)_{Q_{\text {melt }}},(\delta)_{D_{\text {melt }}}$ varies widely depending upon the scheme used, resulting in large variations in the total $\delta$ (as much as $52 \%$ compared to the interscheme mean).

Observations (e.g., Stewart et al. 1984; Mitra et al. 1990; White et al.2010) broadly suggest that the very small $D_{\text {melt }}$ found in the Goddard and the Morrison simulations are unrealistic. However, other limitations may be common to all of the schemes. For instance, melting snowflakes have shapes, fall speeds, and other characteristics that are distinct from those of rain or snow (e.g., Mitra et al. 1990), yet none of these schemes treats melting snow as a separate microphysical species. Furthermore, the process of melting tends to convert the smallest snowflakes into rain first,

\footnotetext{
${ }^{6}$ However, a temporary increase in $D_{\text {melt }}$ is found at the cloud edge in the Morrison et al. simulation. This anomalous feature is not steady in time and its cause is unclear.
} 

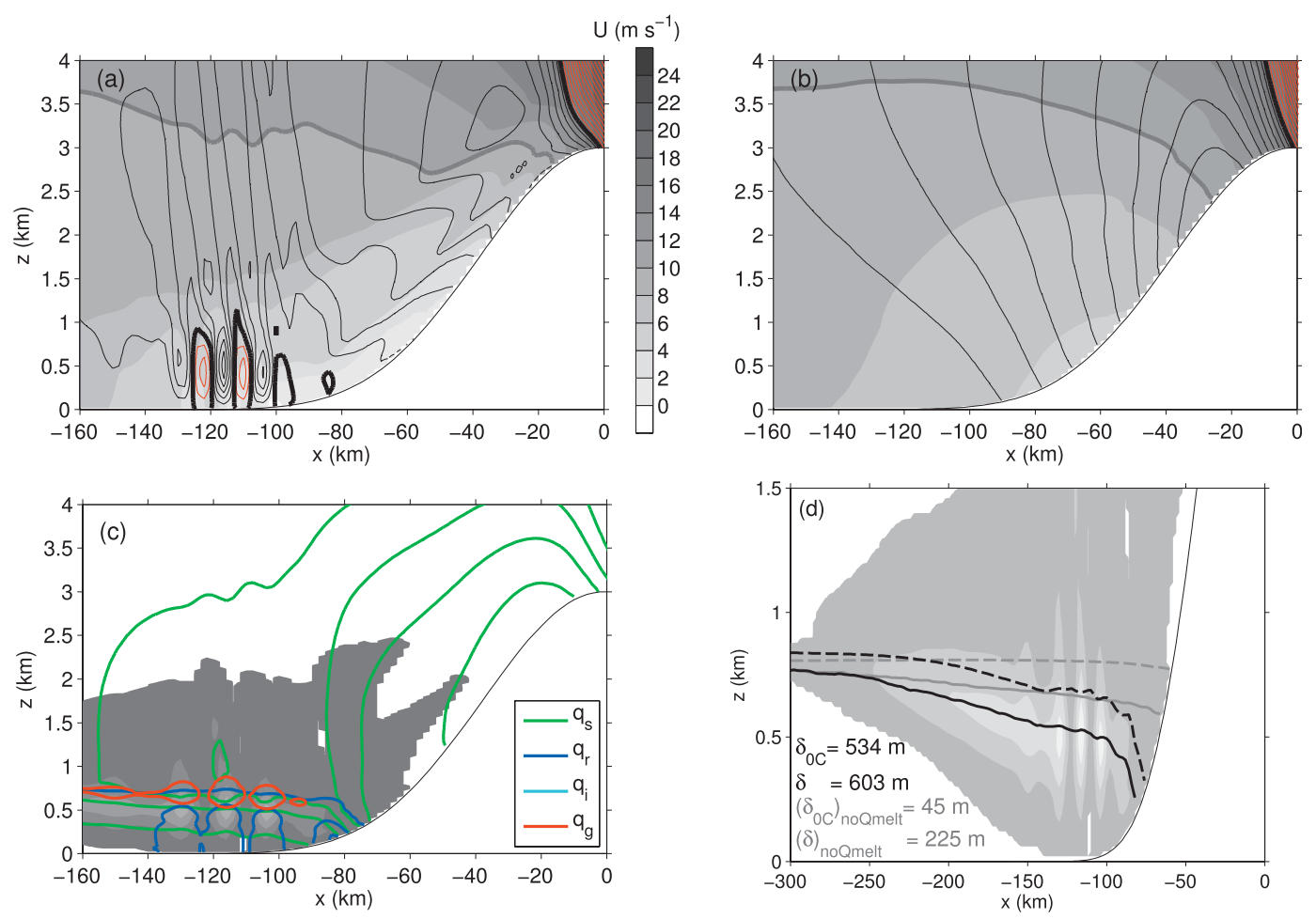

FIG. 19. (a) Results from simulation with $h_{m}=3 \mathrm{~km}, N_{m}=0.005 \mathrm{~s}^{-1}, U=10 \mathrm{~m} \mathrm{~s}^{-1}$, and $\left(N_{m} h_{m}\right) / U=1.5$ averaged from $t=86$ to $87 \mathrm{~h}$, with $u$ winds (shaded, with thick line at $U=10 \mathrm{~m} \mathrm{~s}^{-1}$ ), and $w$ winds (contoured every $5 \mathrm{~cm} \mathrm{~s}^{-1}$, with thick line at $w=0$, and negative values contoured in red). (b) As in (a), but for simulation with $Q_{\text {melt }}$ suppressed. (c) Microphysical mixing ratios, as in Fig. 5a. (d) Detail of melting region with $q_{c}, Z_{S}$, and $Z_{0 \mathrm{C}}$, for simulations with and without $Q_{\text {melt }}$, as in Fig. 10a.

eliminating the lower end of the snow size spectrum, yet these schemes all have size distribution assumptions that do not allow this to occur. Extensive comparisons with observations (e.g., Stewart et al. 1984; Jankov et al. 2009) and more sophisticated models of melting microphysics (Szyrmer and Zawadzki 1999; Theriault et al. 2006) are required to identify which schemes most faithfully represent $Z_{S}$. Until such work is completed $(\delta)_{D_{\text {melt }}}$ will remain, to an extent, fundamentally uncertain.

\section{Discussion}

\section{a. Limitations}

While the semi-idealized WRF simulations produce mesoscale drops in $Z_{S}$ similar to the climatological mean values observed in the Sierra (e.g., Kingsmill et al. 2008), only the preliminary blocked flow simulation produces a lowering of $Z_{S}$ that approaches the extremely large drops $(\sim 1 \mathrm{~km})$ occasionally found in the climatology (Kingsmill et al. 2008) and in case studies (e.g., Marwitz 1987; Medina et al. 2005). This suggests that an important process responsible for the behavior of $Z_{S}$ has been neglected in this study. This could be an effect of blocking but also could relate to other omitted aspects of real orographic storms including boundary layer fluxes, 3D airflow, transient forcing of vertical motion by fronts and synoptic-scale lifting, and small-scale terrain variability.

The lack of surface fluxes and the effects of boundary layer mixing may have important implications, since they may strongly alter the low-level winds and stratification. In particular, very strong surface winds occur in the above simulations because of the use of a free-slip bottom boundary condition. Slower, more realistic lowlevel winds could increase the residence time of air parcels in the melting layer and produce large $(\delta)_{Q_{\text {melt }}}$, as found in section $4 \mathrm{~g}$.

Additionally, this study has not explored the effects of fully 3D airflow patterns. A 3D version of the control simulation with a finite-length ridge (not shown) yields similar results in terms of the magnitude of $\delta$ and the responsible processes (Minder 2010a). Still, further work is required to accurately represent the $3 \mathrm{D}$ effects of airflow blocking for $\left(N_{m} h_{m}\right) / U \geq 1$.

\section{b. Implications}

The simulation by WRF of $\delta_{S}$ values comparable with observations (e.g., Lundquist et al. 2008; Kingsmill et al. 

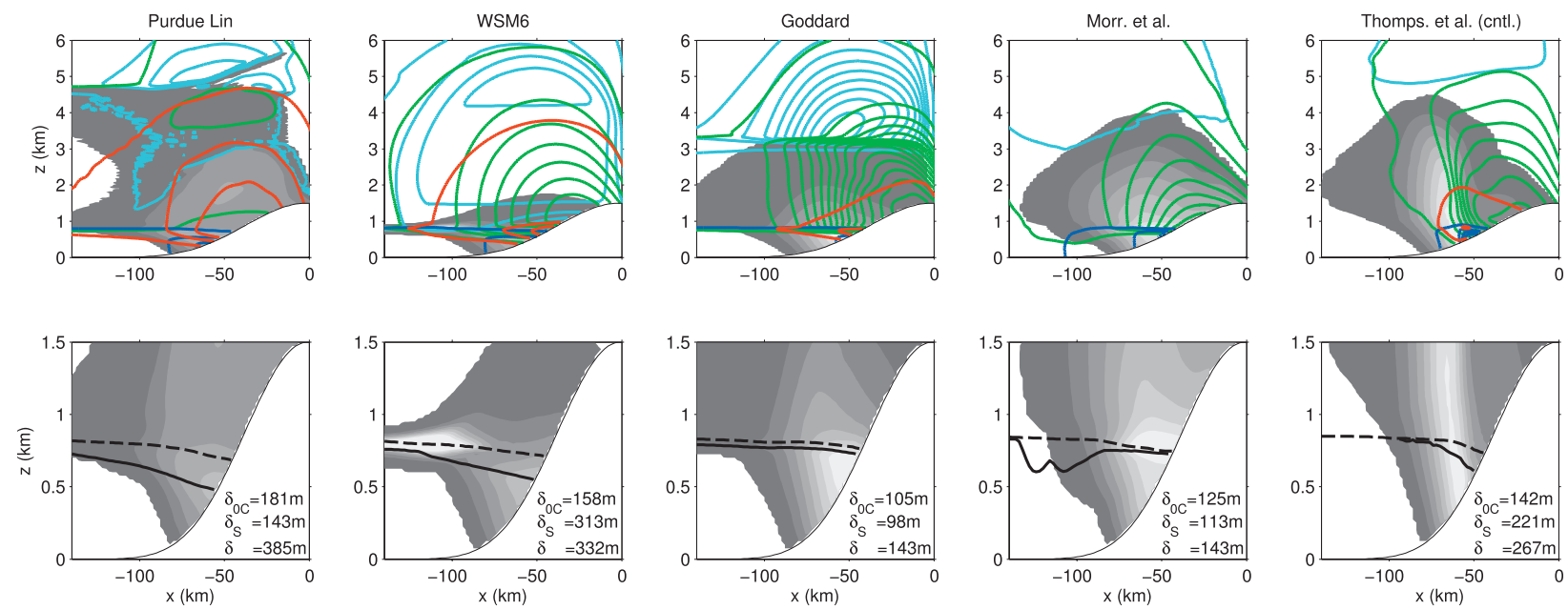

FIG. 20. Results from simulations with different microphysical parameterizations. (top) Mixing ratios $\left(q_{c}, q_{r}, q_{s}, q_{g}\right.$, and $\left.q_{i}\right)$ as in Fig. 5a, except $q_{i}$ is contoured every $0.025 \mathrm{~g} \mathrm{~kg}^{-1}$. (bottom) Detail of melting region showing $Z_{0 \mathrm{C}}$ (dashed), $Z_{S}$ (solid), and $q_{c}$ as in Fig. 6 .

2008) suggests that current mesoscale models are capable of capturing the dominant mesoscale controls on $Z_{S}$. In particular, $(\delta)_{Q_{\text {ad }}}$ and $(\delta)_{Q_{\text {melt }}}$ should be well simulated by models that capture the upwind moisture and temperature profiles, airflow over the windward slopes, and gross pattern of precipitation, but successfully simulating $(\delta)_{D_{\text {melt }}}$ depends on the details of how microphysical processes are parameterized.

The temperature dependence of $\delta$ indicated in Figs. $13 \mathrm{~d}$ and $13 \mathrm{e}$ suggests that mesoscale processes may play an important role in shaping the impacts of climate warming on mountain snowfall. The important role of various mesoscale processes in controlling $Z_{S}$ argues for the use of high-resolution dynamical models in investigations of regional climate. For instance, hydrological models that investigate changes in snowpack by assuming regionally uniform warming and surface temperature thresholds for snow accumulation (e.g., Hamlet and Lettenmaier 1999; Casola et al. 2009; Elsner et al. 2010) may miss important mesoscale influences on mountain snowfall.

\section{Summary and conclusions}

Observations show that a mesoscale lowering of the $0^{\circ} \mathrm{C}$ isotherm $Z_{0 \mathrm{C}}$ and the snow line $Z_{S}$ over the windward slopes is a pervasive feature of mountain weather and climate (Marwitz 1987; Medina et al. 2005; Lundquist et al. 2008; Kingsmill et al. 2008) and is large enough to have important implications for mountain hydroclimate. Three physical mechanisms appear to be responsible for this behavior: 1) under stable stratification, adiabatic cooling of rising air results in colder temperatures, and lower $Z_{0 \mathrm{C}}$, over the mountain than upwind;
2) orographic enhancement of precipitation over the windward slopes results in a localized cooling of the air by melting of frozen hydrometeors that lowers $Z_{0 \mathrm{C}}$ relative to the upwind; and 3) orographic enhancement of precipitation over the windward slopes results in frozen hydrometeors that descend farther below $Z_{0 \mathrm{C}}$ before melting into rain than in the upwind.

This study has used semi-idealized simulations with a mesoscale numerical atmospheric model to diagnose the processes responsible for determining $Z_{S}$ on the mesoscale, to quantify their relative importance, and to investigate their sensitivities to atmospheric conditions and terrain geometry. These simulations have reproduced a mesoscale lowering of $Z_{S}$ similar to that found in observations. Results reveal that all three of the above processes may play an important role in determining $\delta$.

Contributions from the various processes change depending on the mountain, storm, or climate. For long ridges, large drops of $Z_{S}$ are favored by flows with strong stratification, warm temperatures, and moderate relative humidities, and by mountains that are wide. Taken together, the simulated sensitivities help to explain the large variability in $\delta_{S}$ found in observations. Of particular interest is the simulated increase in $\delta$ with temperature, since such an effect could act to buffer mountain hydroclimates against the impacts of climate warming. The microphysical parameterization chosen has a large impact on the simulation of $Z_{S}$ over topography, representing an important source of uncertainty in simulations of mountain snowfall.

Additional aspects of mountain precipitation neglected in this study, such as boundary layer fluxes and fully 3D airflow, are probably required to represent the full range of behavior found in real orographic storms (such 
as kilometer-scale drops in $Z_{S}$ ) and will be investigated in future work. For instance, initial results suggest that low-level flow deceleration associated with blocking may greatly amplify the impact of latent cooling from melting and help produce large drops in $Z_{S}$. Nevertheless, this study presents a framework for how the various mesoscale controls on $Z_{S}$ can be quantified and understood, even in more complex scenarios. Using this as a foundation, future work will add additional layers of realism to the simulations and synthesize model results with field observations to give a more complete understanding of the rain-snow transition over mountains.

\section{Acknowledgments. Mark Stoelinga and Jessica} Lundquist provided comments that improved the manuscript. This work also benefited from discussions with researchers from NOAA-ESRL's HMT-west group. The authors acknowledge support from NSF Grants EAR-0642835 and ATM-0836316.

\section{REFERENCES}

Anderson, E. A., 1976: A point energy and mass balance model of a snow cover. NOAA Tech. Rep. 19, 150 pp.

Arendt, A., J. Walsh, and W. Harrison, 2009: Changes of glaciers and climate in northwestern North America during the late twentieth century. J. Climate, 22, 4117-4134.

Barnett, T. P., J. C. Adam, and D. P. Lettenmaier, 2005: Potential impacts of a warming climate on water availability in snow-dominated regions. Nature, 438, 303-309, doi:10.1038/ nature04141.

Barthazy, E., and R. Schefold, 2006: Fall velocity of snowflakes of different riming degree and crystal types. Atmos. Res., 82, 391-398, doi:10.1016/j.atmosres.2005.12.009.

Bell, G. D., and L. F. Bosart, 1988: Appalachian cold-air damming. Mon. Wea. Rev., 116, 137-161.

Bousquet, O., and B. F. Smull, 2003: Observations and impacts of upstream blocking during a widespread orographic precipitation event. Quart. J. Roy. Meteor. Soc., 129, 391-409, doi:10.1256/qj.02.49.

Casola, J., L. Cuo, B. Livneh, D. Lettenmaier, M. Stoelinga, P. Mote, and J. Wallace, 2009: Assessing the impacts of global warming on snowpack in the Washington Cascades. J. Climate, 22, 2758-2772.

Chen, S. H., and W. Y. Sun, 2002: A one-dimensional time dependent cloud model. J. Meteor. Soc. Japan, 80, 99-118.

Colle, B. A., 2004: Sensitivity of orographic precipitation to changing ambient conditions and terrain geometries: An idealized modeling perspective. J. Atmos. Sci., 61, 588-606.

—, and Y. G. Zeng, 2004a: Bulk microphysical sensitivities within the MM5 for orographic precipitation. Part I: The Sierra 1986 event. Mon. Wea. Rev., 132, 2780-2801.

$\longrightarrow$, and $-2004 \mathrm{~b}$ : Bulk microphysical sensitivities within the MM5 for orographic precipitation. Part II: Impact of barrier width and freezing level. Mon. Wea. Rev., 132, 2802-2815.

, M. F. Garvert, J. B. Wolfe, C. F. Mass, and C. P. Woods, 2005: The 13-14 December 2001 IMPROVE-2 event. Part III: Simulated microphysical budgets and sensitivity studies. J. Atmos. Sci., 62, 3535-3558.
Diaz, H. F., J. K. Eischeid, C. Duncan, and R. S. Bradley, 2003: Variability of freezing levels, melting season indicators, and snow cover for selected high-elevation and continental regions in the last 50 years. Climatic Change, 59, 33-52.

Durran, D. R., and J. B. Klemp, 1982: On the effects of moisture on the Brunt-Väisälä frequency. J. Atmos. Sci., 39, 2152-2158.

Elsner, M., and Coauthors, 2010: Implications of 21st century climate change for the hydrology of Washington State. Climatic Change, 102, 225-260, doi:10.1007/s10584-010-9855-0.

Epifanio, C. C., and D. R. Durran, 2001: Three-dimensional effects in high-drag-state flows over long ridges. J. Atmos. Sci., 58, 1051-1065.

Findeisen, W., 1940: The formation of the $0^{\circ} \mathrm{C}$ isothermal layer in fractocumulus and nimbostratus. Meteor. Z., 57, 49-54.

Galewsky, J., 2008: Orographic clouds in terrain-blocked flows: An idealized modeling study. J. Atmos. Sci., 65, 3460-3478, doi:10.1175/2008JAS2435.1.

Garvert, M. F., C. P. Woods, B. A. Colle, C. F. Mass, P. V. Hobbs, M. T. Stoelinga, and J. B. Wolfe, 2005: The 13-14 December 2001 IMPROVE-2 event. Part II: Comparisons of MM5 model simulations of clouds and precipitation with observations. J. Atmos. Sci., 62, 3520-3534.

Grubišić, V., R. K. Vellore, and A. W. Huggins, 2005: Quantitative precipitation forecasting of wintertime storms in the Sierra Nevada: Sensitivity to the microphysical parameterization and horizontal resolution. Mon. Wea. Rev., 133, 2834-2859.

Hahn, R., and C. Mass, 2009: The impact of positive-definite moisture advection and low-level moisture flux bias over orography. Mon. Wea. Rev., 137, 3055-3071.

Hamlet, A. F., and D. P. Lettenmaier, 1999: Effects of climate change on hydrology and water resources in the Columbia River basin. J. Amer. Water Resour. Assoc., 35, 1597-1623.

$\longrightarrow$, and - 2007: Effects of 20th century warming and climate variability on flood risk in the western U.S. Water Resour. Res., 43, W06427, doi:10.1029/2006WR005099.

—, P. W. Mote, M. P. Clark, and D. P. Lettenmaier, 2005: Effects of temperature and precipitation variability on snowpack trends in the western United States. J. Climate, 18, 4545-4561.

Hong, S.-Y., and J. Lim, 2006: The WRF single-moment 6-class microphysics scheme (WSM6). J. Korean Meteor. Soc., 42, 129-151.

_ J. Judhia, and S.-H. Chen, 2004: A revised approach to ice microphysical processes for the bulk parameterization of clouds and precipitation. Mon. Wea. Rev., 132, 103-120.

Houze, R., 1993: Cloud Dynamics. Academic Press, 573 pp.

Ikeda, K., and Coauthors, 2009: Simulation of seasonal snowfall over Colorado. Atmos. Res., 97, 462-477.

Jankov, I., J.-W. Bao, P. Neiman, P. Schultz, H. Yuan, and A. White, 2009: Evaluation and comparison of microphysical algorithms in ARW-WRF model simulations of atmospheric river events affecting the California coast. J. Hydrometeor., 10, $847-870$.

Jiang, Q., 2003: Moist dynamics and orographic precipitation. Tellus, 55A, 301-316.

— precipitation. J. Atmos. Sci., 60, 1543-1559.

Kingsmill, D., A. White, D. Gottas, and P. Neiman, 2008: Spatial variability of the snow level across the northern California Sierra Nevada. Extended Abstracts, 13th Conf. on Mountain Meteorology, Whistler, BC, Canada, Amer. Meteor. Soc., 6A.3. [Available online at http://ams.confex.com/ams/13MontMet17AP/ techprogram/paper_140814.htm.] 
Kirshbaum, D., and R. Smith, 2008: Temperature and moiststability effects on midlatitude orographic precipitation. Quart. J. Roy. Meteor. Soc., 134, 1183-1199, doi:10.1002/qj.274.

Klemp, J., J. Dudhia, and A. Hassiotis, 2008: An upper gravitywave absorbing layer for NWP applications. Mon. Wea. Rev., 136, 3987-4004.

Lalas, D. P., and F. Einaudi, 1973: On the stability of a moist atmosphere in the presence of a background wind. J. Atmos. Sci., 30, 795-800.

Lin, C. A., and R. E. Stewart, 1986: Mesoscale circulations initiated by melting snow. J. Geophys. Res., 91, 13 299-13 302.

Lin, Y., and B. Colle, 2009: The 4-5 December 2001 IMPROVE-2 event: Observed microphysics and comparisons with the Weather Research and Forecasting model. Mon. Wea. Rev., 137, 1372-1392.

Locatelli, J., and P. Hobbs, 1974: Fall speeds and masses of solid precipitation particles. J. Geophys. Res., 79, 2185-2197.

Lundquist, J., P. Neiman, B. Martner, A. White, D. Gottas, and F. Ralph, 2008: Rain versus snow in the Sierra Nevada, California: Comparing Doppler profiling radar and surface observations of melting level. J. Hydrometeor., 9, 194-211.

Marwitz, J. D., 1983: The kinematics of orographic airflow during Sierra storms. J. Atmos. Sci., 40, 1218-1227.

_ 1987: Deep orographic storms over the Sierra Nevada. Part I: Thermodynamic and kinematic structure. J. Atmos. Sci., 44, 159-173.

Matsuo, T., and Y. Sasyo, 1981: Melting of snowflakes below the freezing level in the atmosphere. J. Meteor. Soc. Japan, 59, 10-24.

Medina, S., B. F. Smull, R. A. Houze, and M. Steiner, 2005: Crossbarrier flow during orographic precipitation events: Results from MAP and IMPROVE. J. Atmos. Sci., 62, 3580-3598.

Miglietta, M. M., and R. Rotunno, 2005: Simulations of moist nearly neutral flow over a ridge. J. Atmos. Sci., 62, 1410-1427.

_ and _ 2006: Further results on moist nearly neutral flow over a ridge. J. Atmos. Sci., 63, 2881-2897.

Minder, J., 2010a: On the climatology of orographic precipitation in the mid-latitudes. Ph.D. thesis, University of Washington, $187 \mathrm{pp}$.

_ 2010b: The sensitivity of mountain snowpack accumulation to climate warming. J. Climate, 23, 2634-2650.

Mitra, S. K., O. Vohl, M. Ahr, and H. R. Pruppacher, 1990: A wind tunnel and theoretical study of the melting behavior of atmospheric ice particles. IV: Experiment and theory for snow flakes. J. Atmos. Sci., 47, 584-591.

Morrison, H., J. A. Curry, and V. I. Khvorostyanov, 2005: A new double-moment microphysics parameterization for application in cloud and climate models. Part I: Description. J. Atmos. Sci., 62, 1665-1677.

_, G. Thompson, and V. Tatarskii, 2009: Impact of cloud microphysics on the development of trailing stratiform precipitation in a simulated squall line: Comparison of one- and two-moment schemes. Mon. Wea. Rev., 137, 991-1007.

Pierrehumbert, R. T., and B. Wyman, 1985: Upstream effects of mesoscale mountains. J. Atmos. Sci., 42, 977-1003.

Rauber, R. M., 1992: Microphysical structure and evolution of a central Sierra Nevada orographic cloud system. J. Appl. Meteor., 31, 3-24.
Skamarock, W., and M. Weisman, 2009: The impact of positivedefinite moisture transport on NWP precipitation forecasts. Mon. Wea. Rev., 137, 488-494.

- , and Coauthors, 2008: A description of the Advanced Research WRF version 3. NCAR Tech. Note NCAR/TN475+STR, 113 pp.

Smith, R. B., and I. Barstad, 2004: A linear theory of orographic precipitation. J. Atmos. Sci., 61, 1377-1391.

Steenburgh, W. J., C. F. Mass, and S. A. Ferguson, 1997: The influence of terrain-induced circulations on wintertime temperature and snow level in the Washington Cascades. Wea. Forecasting, 12, 208-227.

Steinacker, R., 1983: Diagnose und prognose der Schneefallgrenze (Diagnosing and predicting the snowline). Wetter Leben, 35, 81-90.

Stewart, R. E., J. D. Marwitz, J. C. Pace, and R. E. Carbone, 1984: Characteristics through the melting layer of stratiform clouds. J. Atmos. Sci., 41, 3227-3237.

Svoma, B., 2011: Trends in snow level elevation in the mountains of central Arizona. Int. J. Climatol., 31, 87-94, doi:10.1002/ joc. 2062 .

Szyrmer, W., and I. Zawadzki, 1999: Modeling of the melting layer. Part I: Dynamics and microphysics. J. Atmos. Sci., 56, 35733592

Tao, W. K., and Coauthors, 2003: Microphysics, radiation and surface processes in the Goddard Cumulus Ensemble (GCE) model. Meteor. Atmos. Phys., 82, 97-137, doi:10.1007/s00703001-0594-7.

Theriault, J. M., R. E. Stewart, J. A. Milbrandt, and M. K. Yau, 2006: On the simulation of winter precipitation types. J. Geophys. Res., 111, D18202, doi:10.1029/2005JD006665.

Thompson, G., R. M. Rasmussen, and K. Manning, 2004: Explicit forecasts of winter precipitation using an improved bulk microphysics scheme. Part I: Description and sensitivity analysis. Mon. Wea. Rev., 132, 519-542.

_ P. Field, R. Rasmussen, and W. Hall, 2008: Explicit forecasts of winter precipitation using an improved bulk microphysics scheme. Part II: Implementation of a new snow parameterization. Mon. Wea. Rev., 136, 5095-5115.

Unterstrasser, S., and G. Zängl, 2006: Cooling by melting precipitation in Alpine valleys: An idealized numerical modelling study. Quart. J. Roy. Meteor. Soc., 132,1489-1508, doi:10.1256/ qj.05.158.

Wei, Y. L., and J. Marwitz, 1996: The Front Range blizzard of 1990. Part III: Numerical simulations of melting effects. Mon. Wea. Rev., 124, 2483-2496.

Westrick, K. J., and C. F. Mass, 2001: An evaluation of a highresolution hydrometeorological modeling system for prediction of a cool-season flood event in a coastal mountainous watershed. J. Hydrometeor., 2, 161-180.

White, A. B., D. J. Gottas, E. T. Strem, F. M. Ralph, and P. J. Neiman, 2002: An automated brightband height detection algorithm for use with Doppler radar spectral moments. J. Atmos. Oceanic Technol., 19, 687-697.

, — - A. Henkel, P. Neiman, F. Ralph, and S. Gutman, 2010: Developing a performance measure for snow-level forecasts. J. Hydrometeor., 11, 739-753. 